Western University

Scholarship@Western

Brain and Mind Institute Researchers'

Publications

Brain and Mind Institute

$4-1-2020$

\title{
Sensory inflow manipulation induces learning-like phenomena in motor behavior
}

\author{
Samuele Contemori \\ The University of Queensland \\ Cristina V. Dieni \\ The University of Alabama at Birmingham \\ Jacqueline A. Sullivan \\ The University of Western Ontario, jsulli29@uwo.ca \\ Aldo Ferraresi \\ Università degli Studi di Perugia \\ Chiara Occhigrossi \\ Università degli Studi di Perugia
}

See next page for additional authors

Follow this and additional works at: https://ir.lib.uwo.ca/brainpub

Part of the Neurosciences Commons, and the Psychology Commons

Citation of this paper:

Contemori, Samuele; Dieni, Cristina V.; Sullivan, Jacqueline A.; Ferraresi, Aldo; Occhigrossi, Chiara; Calabrese, Francesco; Pettorossi, Vito E.; Biscarini, Andrea; and Panichi, Roberto, "Sensory inflow manipulation induces learning-like phenomena in motor behavior" (2020). Brain and Mind Institute Researchers' Publications. 297.

https://ir.lib.uwo.ca/brainpub/297 


\section{Authors}

Samuele Contemori, Cristina V. Dieni, Jacqueline A. Sullivan, Aldo Ferraresi, Chiara Occhigrossi, Francesco Calabrese, Vito E. Pettorossi, Andrea Biscarini, and Roberto Panichi 


\title{
New frontiers in translational research: Touchscreens, open science, and the mouse translational research accelerator platform
}

\author{
Jacqueline A. Sullivan ${ }^{1,2,3}$ @ | Julie R. Dumont ${ }^{4,5}$ @ | Sara Memar ${ }^{5}$ | \\ Miguel Skirzewski, ${ }^{4,5}$ | Jinxia Wan ${ }^{6,7}$ | Maryam H. Mofrad ${ }^{3,8}$ |

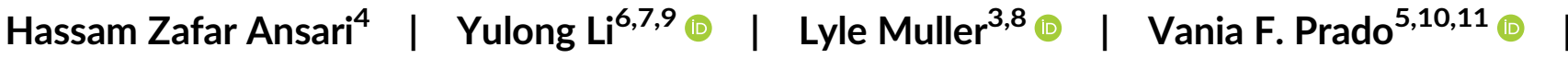

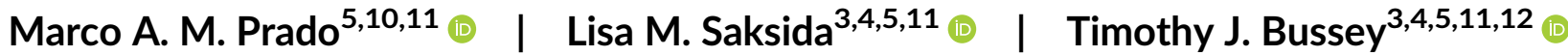

${ }^{1}$ Department of Philosophy, The University of Western Ontario, Ontario, Canada

${ }^{2}$ Rotman Institute of Philosophy, The University of Western Ontario, Ontario,

Canada

${ }^{3}$ Brain and Mind Institute, The University of Western Ontario, Ontario, Canada

${ }^{4}$ BrainsCAN, The University of Western Ontario, Ontario, Canada

${ }^{5}$ Robarts Research Institute, The University of Western Ontario, Ontario, Canada

${ }^{6}$ Division of Sciences, State Key Laboratory of Membrane Biology, Peking University School of Life Sciences, Beijing, China

${ }^{7} \mathrm{PKU}-\mathrm{IDG} / \mathrm{McGovern}$ Institute for Brain Research, Beijing, China

${ }^{8}$ Department of Applied Mathematics, The University of Western Ontario, Ontario,

Canada

${ }^{9}$ Peking-Tsinghua Center for Life Sciences, Academy for Advanced Interdisciplinary Studies, Peking University, Beijing, China

${ }^{10}$ Department of Anatomy and Cell Biology, The University of Western Ontario, Ontario, Canada

${ }^{11}$ Department of Physiology and Pharmacology, The University of Western Ontario, Ontario, Canada

${ }^{12}$ Department of Psychiatry, The University of Western Ontario, Ontario, Canada

Correspondence

Jacqueline A. Sullivan, Department of Philosophy, The University of Western Ontario, Ontario, Canada.

Email: jsulli29@uwo.ca

\begin{abstract}
Many neurodegenerative and neuropsychiatric diseases and other brain disorders are accompanied by impairments in high-level cognitive functions including memory, attention, motivation, and decision-making. Despite several decades of extensive research, neuroscience is little closer to discovering new treatments. Key impediments include the absence of validated and robust cognitive assessment tools for facilitating translation from animal models to humans. In this review, we describe a state-of-the-art platform poised to overcome these impediments and improve the success of translational research, the Mouse Translational Research Accelerator Platform (MouseTRAP), which is centered on the touchscreen cognitive testing system for rodents. It integrates touchscreen-based tests of high-level cognitive assessment with state-of-the art neurotechnology to record and manipulate molecular and circuit level activity in vivo in animal models during human-relevant cognitive performance. The platform also is integrated with two Open Science platforms designed to facilitate knowledge and data-sharing practices within the rodent touchscreen community, touchscreencognition.org and mousebytes.ca. Touchscreencognition.org includes the Wall, showcasing touchscreen news and publications, the Forum, for community discussion, and Training, which includes courses, videos, SOPs, and symposia. To get started, interested researchers simply create user accounts. We describe the origins of the touchscreen testing system, the novel lines of research it has facilitated, and its increasingly widespread use in translational research, which is attributable in part to knowledge-sharing efforts over the past decade. We then identify the unique features of MouseTRAP that stand to potentially revolutionize translational research, and describe new initiatives to partner with similar platforms such as McGill's M3 platform (m3platform.org).
\end{abstract}




\section{KEYWORDS}

circuits, cognition, collaboration, community building, data sharing, knowledge sharing, mouse models, neurodegenerative disease, neuropsychiatric disease, neurotechnology, open science, reproducibility, standardization, touchscreens, translation

\section{1 | INTRODUCTION}

Many neurodegenerative, neuropsychiatric and other brain disorders are accompanied by impairments in high-level cognitive functions including memory, attention, motivation and decision-making. Patients with these disorders may have difficulty dividing, switching or maintaining attention, remembering persons, objects and locations or modifying their behavior when appropriate. They thus may be unable to care for themselves, complete even the simplest everyday tasks and maintain meaningful interpersonal relationships. These diseases contribute to a severely diminished quality of life for these patients and their caregivers. Effective treatments for them are desperately needed.

Despite several decades of extensive research to identify the neural mechanisms that underlie functional impairments in brain disorders and the establishment of several interdisciplinary initiatives aimed at propelling translational research forward, neuroscience is little closer to discovering new treatments. On the one hand, the lack of progress is surprising given the recent rise in revolutionary new tools for intervening in and visualizing neural circuit activity in vivo in animal models and the development of next generation mouse models that bear greater genetic and functional similarity to the human diseases they are designed to model. On the other hand, the current lull in discovery is perhaps unsurprising, for several reasons. First, until fairly recently, cognitive testing tools for reliably and comprehensively assessing high-level cognitive functions and disease-related cognitive impairments in mice were not available. Second, despite the enormous quantity of data that translational research has produced, prepublication knowledge and data sharing are not common practices, and rodent behavioral paradigms are still considered to lack robustness. Third, although developing and testing novel therapies for cognitive impairments requires reproducibility, it is uncommon for rodent behavioral researchers to standardize their research practices in ways that facilitate comparison of findings across labs and thus advance mechanistic discovery.

As we explain in this review, this situation is rapidly changing, and the use of the standardized cognitive testing of rodents is on the rise. ${ }^{1}$ The rodent touchscreen approach is uniquely suited to this application. Touchscreens are being combined with cutting-edge visualization and intervention techniques that allow unprecedented access to and control over molecular and circuit level activity in vivo in awake behaving animals. Open Science Platforms have been created that offer rodent behavioral researchers an unprecedented opportunity to share knowledge and technical expertise and to upload, visualize and comparatively analyze their data to gain a broader and more detailed understanding of molecular, cellular and circuit-level activity in normal and diseased brains. Such developments have the potential to greatly facilitate cross-species translational research and propel forward mechanistic and therapeutic discovery.

We begin by identifying a set of widely agreed upon benchmarks for translational research. We then explain how, during the past three decades, researchers have sought to meet these benchmarks by developing, validating, and using novel touchscreen-based testing methods. We go on to describe the newly-minted mouse translational research accelerator platform (MouseTRAP), which is centered on the touchscreen testing system and highlight its distinctive features. MouseTRAP is a service platform that operates within the Rodent Cognition Core at Western University and combines the use of our touchscreen-based system with cutting-edge neurotechnology that allows molecular and circuit-level activity to be measured and manipulated with millisecond precision in the brains of healthy mice and mouse models of disease during human-relevant cognitive performance. Another important feature that sets MouseTRAP apart is its integration with two novel Open Science platforms, touchscreencognition.org and mousebytes.ca., which are designed to facilitate knowledge and data sharing within the rodent touchscreen community. We end by describing new initiatives to partner with similar platforms such as McGill's M3 platform (m3platform.org).

\section{1 | Benchmarks for translational cognitive neuroscience research}

In the first two decades of the 21st century, several major initiatives were established in order to fast-track the development of treatments for cognitive impairments in neuropsychiatric and neurodegenerative disorders. Representative examples include cognitive neuroscience treatment research to improve cognition in Schizophrenia (CNTRICS), ${ }^{2,3}$ NEWMeds, ${ }^{4}$ the US National Institute of Health's Toolbox (NIH Toolbox) ${ }^{5,6}$ and the US National Institute of Mental Health's Research Domain Criteria Project (NIMH RDoC). ${ }^{7,8}$ These initiatives have variously brought together preclinical translational behavioral neuroscientists, clinical researchers, cognitive neuroscientists working with humans and/or animal models, systems neuroscientists and members of the pharmaceutical industry with an aim to (a) develop more representative mouse models of neurodegenerative and neuropsychiatric disease, (b) improve tools for the assessment of cognition in humans and mice, and (b) increase the similarity of tools used for the behavioral assessment of cognitive functions across researchers and species. These initiatives have prompted researchers to make explicit a number of desirables for cognitive assessment tools used in translational research. 
First, a primary hurdle to translating results from rodent to human behavioral studies, which we have emphasized in our previous work, is the mismatch between tools used to assess cognition in rodents and humans. There is now widespread agreement that the more similar the tasks for assessing cognition are across species (face validity), the more likely it is that the same cognitive functions and neural circuits will be involved. But even if tasks used to probe cognitive functions in different species appear roughly similar, it is a separate question whether they are suitable for individuating cognitive capacities (construct validity) and identifying the neural circuits that mediate task performance (neurocognitive validity). ${ }^{9}$ Achieving construct validity is widely understood to be an iterative process, as findings from exploratory and hypothesis-driven experiments often prompt task refinement and/or construct revision. Construct validity may be enhanced by good task design that includes, for example, parametric manipulation of variables that load on the construct of interest, such as delay/retention intervals to test for delay-dependent effects that can be interpreted as changes in memory, and manipulations of stimulus detectability to study attention. ${ }^{10,11}$

Translational researchers must also establish the construct and neurocognitive validity of cognitive assessment tools across species. Translational neurocognitive validity ${ }^{9}$ is essential for determining if the same circuits are involved in task performance across species. Ideally, translational researchers want to be able to predict that a treatment that works in rescuing a cognitive deficit in a rodent model of disease will be effective in rescuing that deficit in human clinical populations (translational predictive validity). Cognitive assessment tools should also be sensitive to dose-dependent effects of drugs on cognitive abilities, so as to increase the likelihood that a drug that improves cognition in a rodent model has a greater chance of having a positive impact in the human case. Achieving translational neurocognitive validity is also an iterative process, as it requires investigators working in human and nonhuman animal cognition to toggle back and forth between human and rodent tasks to refine them in order to facilitate translation while ensuring that other dimensions of validity are maintained. ${ }^{3,9}$

Reproducible results are also essential. One hurdle to progress in translational research is a historical lack of emphasis on replicating results and a failure to standardize cognitive assessment tools across research groups. In human and animal cognitive studies, although different research groups might use the same cognitive task or assessment tool for investigating a cognitive capacity (e.g., working memory), features of the overarching and specific protocols associated with use of that tool (e.g., types of stimuli used, intertrial intervals, investigator interactions with participants) commonly vary across research groups. Yet even subtle differences in protocols could potentially result in subtle differences in the cognitive processes and underlying neural mechanisms being investigated. Lack of standardization is a problem.

It is not enough to detect effects in a single lab; ideally we want many labs to run the same experiments in order to determine whether effects observed in a single lab are real or chimerical. It is thus fundamental to have a different investigator working in a different research context run the same experiment, following the exact same protocol. If another group of scientists can use an experimental design, paradigm, protocol and statistical analysis techniques and obtain similar results as in another research study, it increases confidence that the findings are not idiosyncratic to a specific experimental context. This is why methodological and data transparency in the form of Open Science initiatives and on-line platforms and collaborative work across laboratories to directly replicate experiments (adhering to the same standards of reliability that were upheld in the original research study) is so important. It is especially important in translational research, given that determining the efficacy of a drug for treating cognitive impairments requires pre-clinical trials in rodents, across which results must be replicated before moving to human clinical trials, which also require replication.

It is worth emphasizing that meeting the aforementioned benchmarks is not possible in a single laboratory or research study; it instead requires an unprecedented amount of collaboration and coordination of research practices within and across research groups working at different levels of analysis and with different species and consisting of investigators with diverse theoretical backgrounds and technical expertise. ${ }^{12}$ It also takes a significant amount of resources and time to gradually hit each of these benchmarks to reach the point at which discovery of novel therapeutics is possible.

Our aim in the rest of this paper is to describe how we have sought to meet these benchmarks for translational research using the touchscreen cognitive testing method and initiatives based on this approach.

\section{2 | The touchscreen approach to cognition: From nonhuman primates to humans to rodents and beyond}

Nearly two decades prior to the establishment of the CNTRICS, NewMeds and RDoC initiatives, a group of neuropsychologists at Cambridge university developed a suite of computerized touchscreenbased tasks, the Cambridge neuropsychological test automated battery (CANTAB), in order to develop cognitive profiles for patients with neurodegenerative diseases. While other cognitive testing batteries were available, what set CANTAB apart was the emphasis Cambridge researchers placed on translational potential of the battery. At that time, there was a heated debate about whether observed structurefunction differences across species were attributable to differences in the cognitive tools used to assess cognitive functions across species or to bona fide structure-function differences. ${ }^{13-16}$ In nonhuman primate tasks that were used to assess working memory, attention, and planning, monkeys were presented with visual stimuli on a computer screen and were required to select the correct stimulus with a finger press and received positive feedback for accurate responses. Cambridge researchers modeled CANTAB tasks after these nonhuman primate tasks (and vice-versa) based on the rationale that the more similar cognitive tasks are across species (face validity), the greater the likelihood that the same cognitive processes and underlying neural mechanisms will be involved in performance on those tasks 
(i.e., neurocognitive validity). While increasing the face validity of cognitive tasks across species does not guarantee that the cognitive functions and neural mechanisms involved in task performance will be identical (see discussion above), it is arguably one of the best heuristics researchers have to increase the likelihood that they will be.

The development of the CANTAB task battery also was shaped by a concern for construct validity-or what researchers described as a careful componential analysis of the cognitive functions of memory, attention and planning into their sub-component processes. Each task was developed with an eye towards precisely individuating and measuring deficits in the cognitive function it was designed to measure.

The touchscreen task battery approach was also regarded as having certain advantages with respect to reliability over other approaches to assessing cognition. Ensuring that stimuli, required responses on the part of the subject and feedback are consistent across tasks and conditions, allows potential confounds to be ruled out when subject performance across tasks in the battery are compared. Because the tests are automated, they can be used to measure behavioral response latencies with milli-second accuracy, increasing the sensitivity of the tasks for the detection of cognitive impairments. Although a test administrator must be present to explain and supervise the tests, automation also decreases the possibility of certain kinds of confounds that may occur as a result of interactions between scientists and their subjects during the course of an experiment, thus increasing reliability.

The CANTAB testing battery was originally used to characterize cognitive impairments in persons with Alzheimer-type dementia and Parkinson's disease. ${ }^{17-19}$ It has since been used to assess cognition in a number of conditions including Attention Deficit Disorder, Autism Spectrum Disorder, Depression and Affective Disorders, Huntington's disease and Schizophrenia. CANTAB tests have been shown to have predictive validity with respect to cognitive decline in persons with neurodegenerative disorders. Tests from the battery also have been used in the context of neuroimaging studies to illuminate the neural substrates underlying cognitive deficits in patients with neurodegenerative and neuropsychiatric diseases and to assess the impact of certain drugs on task performance. Today, the tests are the most widely used computerized measures of cognition in humans, (https://www. cambridgecognition.com/cantab/cognitive-tests/) and computerized training batteries also are regarded as promising tools for improving cognition in persons with neuropsychiatric, neurodegenerative and other brain disorders (e.g., concussion). One example of a computerized training battery, CogMed ${ }^{20,21}$ is aimed at improving working memory and attention in persons with neurodevelopmental disorders and/or intellectual disabilities (https://www.cogmed.com).

In the 1990s, the researchers who developed CANTAB were optimistic that the battery, when used in combination with imaging techniques, would "yield a wealth of data correlating structure and function." ${ }^{16}$ Yet, developing treatments for human cognitive dysfunction requires tools for intervening in the brain and assessing cognition in nonhuman animals, and at Cambridge in the early 1990s the drive to develop computerized touchscreen-based tasks for rodents began. At that time, the predominant tasks used to investigate cognition, cognitive impairments and their neural underpinnings in rodents included mazes (e.g., Morris water maze), foraging and associative learning tasks (e.g., fear conditioning). Although these tasks shed some light on the mechanisms of cognition in the mammalian brain, differences in task type, task parameters and stimuli used to assess cognition in rodents compared to humans were obstacles to relating more precise findings about cognitive functions across species. So, too, was the fact that many of these tasks were aversively motivated, making stress a potential confound. Moreover, the kinds of high-level cognitive functions that are impaired in human neurodegenerative and neuropsychiatric diseases, for which experiments with CANTAB had already provided evidence, outstripped the types of cognitive functions that could be assessed in rodents using conventional methods. What were needed were tests to behaviorally assess rodent cognition that involved cognitive functions similar to those shown to be impaired in humans with neurodegenerative and neuropsychiatric disease. Additionally, there was no reason to think that rodents were incapable of more complex forms of cognition of the kind being tested by means of computerized touchscreen based visual tasks in humans and nonhuman primates, only skepticism that rodents, given their relatively poor vision, would respond to visual stimuli presented on a computer screen.

Despite such skepticism, it had been noted that when rats were placed into pigeon touchscreen operant chambers, "[they were] able to respond and attend to [...] computer graphic stimuli presented on a touch-sensitive screen"22 This initial discovery spurred the publication of the first computerized automated rodent operant touchscreen apparatus at Cambridge in $1994^{22}$ (another group introduced a pressure-sensitive touch window apparatus that same year ${ }^{23}$ ), a similar apparatus for testing mice and mouse models of neurodegenerative and neuropsychiatric disorders in $2001,{ }^{24}$ and the later development of a modified version of the apparatus that can be used in combination with novel intervention (e.g., DREADDS, optogenetics) and visualization (e.g., fiber photometry, miniscopes) techniques to intervene in and observe brain activity in vivo while rodents perform cognitive tasks.

The development of the rodent touchscreen cognitive testing platform sought to achieve face validity with respect to human tests such as those in the CANTAB battery in order to facilitate the translation of findings from rodents to humans. Rodent touchscreen-based tasks involve visual stimuli that are presented on a touch-sensitive screen, similar to human touchscreen tasks. Rodents respond directly to visual stimuli with nose-pokes, and positive reinforcers such as strawberry milkshake or food pellets are delivered for correct choices, much like human subjects receive positive visual feedback and monkeys receive food rewards on touchscreen tasks when they make a correct choice with a finger press.

Touchscreens have a number of important advantages that have been noted previously, and in a number of articles in this special issue of Genes, Brains, and behavior. ${ }^{25}$ First, in common with some other methods such as standard operant chambers, the tasks are automated, providing accuracy of task parameters and measures, and eliminating experimenter errors that are characteristic of more conventional 
techniques in which animals and testing materials such as stimuli often undergo extensive handling during testing. It is also nonaversive compared to other tasks used to assess rodent cognition. This is particularly important as experiments can easily be confounded by the physiological changes that an animal undergoes due to stress caused by cool water, electric shock or head fixation. ${ }^{26-28}$ Another advantage is that, compared to tasks like the Morris Water Maze and contextual fear-conditioning, touchscreens readily may be used to assess cognitive impairments in disabled and motorically impaired animals. ${ }^{29}$ The touchscreen method is also high-throughput; automation allows an investigator to run many touchscreen experiments simultaneously. Infrared beams and video tracking devices that are used to monitor an animal's behavior while performing in the apparatus also provide a wealth of data that may be probed using different data analysis techniques. And unlike other behavioral phenotyping approaches, all tests feature the same test setting, stimuli, responses, and reinforcers, allowing comparison across test unconfounded by changes in the basic methodology.

During the past two decades, rodent touchscreens have been at the center of a number of ongoing lines of research. Importantly, a number of optimization and validation studies have been undertaken to systematically determine the kinds of task parameters that may impact learning in the apparatus. ${ }^{30}$ In one research study, one set of experiments was aimed at determining whether rats have biases for certain touchscreen visual stimuli, which might account for task performance and negatively impact learning in the apparatus. ${ }^{30}$ Another set was aimed at determining the optimal stimulus size for performance in the apparatus. ${ }^{30}$ Other experiments sought to determine the impact of inter-trial intervals, trials per session and trial initiation requirements on learning with an eye towards selecting optimal parameters for learning. ${ }^{30}$ Additional studies have included research to determine whether there are differences in performance on touchscreen-based tasks across different mouse strains, the role that stressors have on different strains ${ }^{31}$ and the role of reinforcer type and strength on learning in touchscreens. ${ }^{32,33}$ Touchscreen researchers also have sought to determine if sex differences impact task performance, which is particularly important for obtaining findings that are generalizable from rodents to the human population (i.e., external validity). ${ }^{25,34,35}$ During the past several decades, touchscreen research also has illuminated behavioral differences in task performance across species. For example, mice tend to be less impulsive in the touchscreen and so better at tasks in which they have to withhold responding (e.g., 5-choice and CPT [See Table

for relevant citations]). In fact, the rat touchscreen apparatus has an additional 'shelf' to slow the rats down and speed learning (Bussey et al 1994), whereas mice do not need this shelf.

Exploratory translational research has been directed at developing new touchscreen-based tasks for rodents, in some cases using human CANTAB or CANTAB-like tasks as starting points and iterating back and forth between human and rodent versions of the tasks in order to achieve face validity between the two. Using this strategy, a number of novel touchscreen tasks for rats and mice have been developed, including paired-associates learning (PAL), ${ }^{39,42}$ the location discrimination (LD) test of pattern separation, ${ }^{54}$ trial-unique nonmatching-to-location (TUNL), the rodent continuous performance task $(\mathrm{rCPT})^{80}$ and 5 -Choice serial reaction time (5-CSRTT) to name only a handful. These tasks are components of a testing battery that can be used to study a variety of cognitive functions including: reward learning, memory, perceptual discrimination, object-place associative learning, attention, impulsivity, compulsivity, extinction, simple Pavlovian conditioning, and other constructs. ${ }^{25}$ This growing battery of tasks was first described in $2012,{ }^{25,121}$ became a part of the NEWMEDS initiative in $2015^{122}$ and has since grown to over 30 tasks (See Table 1).

Given the flexibility of the touchscreen operant platform for developing novel behavioral tasks, new tasks are being designed and validated all the time and once a task is developed, it may serve as a single behavioral tool for use in a research study or be used as a part of the larger testing battery.

Using a battery approach, as is done with human CANTAB tasks, also increases the reliability of rodent touchscreen experiments. Ensuring that the apparatus, stimuli, required responses and reward are consistent across tasks and conditions, allows these potential confounds to be ruled out when a rodent's performance across tasks in the battery is compared. For example, if an animal fails an object-place paired associative learning task but performs well on visual discrimination and reversal, it is unlikely that the paired associate learning impairment is due to a difficulty with perceptually discriminating objects or generalized deficit in learning ability. A major advantage of the battery approach is that it can be used to provide a cognitive profile of an animal model of disease and to identify rescuable deficits that can serve as the focus of drug testing. Touchscreens have been used to characterize cognitive impairments in a number of rodent models of neurodegenerative and neuropsychiatric disease including models of Huntington's disease, ${ }^{29}$ addiction, ${ }^{109}$ Alzheimer's disease $e^{42,121}$ to name only a few.

Another advantage of the touchscreen system is that it has and continues to evolve in line with the latest developments in neurotechnology and mouse models of disease. To date, touchscreen-based tasks have been used in combination with in vivo electrophysiology, optogenetics, fiber photometry and miniscopes to measure neural activity during task performance and to assess the impact of in vivo causal interventions. Findings from such experiments may be compared to findings from noninvasive imaging experiments in healthy and clinical human populations as a means to determine if homologous structures, circuits, cell populations and molecules are implicated in cognition and cognitive impairments across species.

A major goal of the touchscreen approach is to facilitate translation from animal models of disease to the human diseases they are designed to model. In a proof-of-concept study, touchscreen researchers established that the performance of transgenic mice and humans with a homologous gene deletion performed similarly on an object place paired associates learning task. ${ }^{123}$ In other studies, selective vigilance decrements in the 5 -CSRTT were rescued by anticholineasterase in a mouse model of Alzheimer's disease, mirroring rescue of the same vigilance impairment on the same task by the same 
TAB LE 1 Some available touchscreen-based tests for use with rats and/or mice, with selected references. The list of tasks is not exhaustive, nor is the list of references for each task. The table is organized by cognitive construct, but in many cases, tasks can be used to study multiple constructs, via manipulation of parameters that load on different constructs (for example the 5-CSRTT is used to study attention and also cognitive flexibility/impulsivity)

\section{List of rodent touchscreen tests}

A. Learning and memory:

1. Pairwise visual discrimination learning

2. Object-location paired associates learning

\section{Working memory}

a. Spatial

1. Trial-Unique nonmatching-to-location (TUNL) task)

2. Continuous trial unique nonmatchingto-location task (cTUNL)

3. Delay match to position (DNMTP)

b. Nonspatial nonspatial nonmatching to sample

4. Location discrimination (spatial pattern separation)

5. Spontaneous (Novel) object recognition

6. Visuomotor conditional learning (VMCL)

7. Automated search task (AST/ASAT/ virtual water maze task)

8. Heterogeneous long sequence task

9. Transverse patterning

10. Category learning

11. Transitive Inference

B. Attention:

1. 5-choice serial reaction time task (5-CSRTT)

2. Continuous performance test (including Flanker task)

\section{5-choice CPT}

4. Sustained attention task (SAT)

5. Spatial probability task (endogenous)

6. Flanker task (exogenous)

7. Posner cuing task

C. Decision making:

1. Rodent gambling task

2. Risky decision-making task (RDT)

3. Delay discounting

4. Probability discounting

5. Effort-related choice/decision

6. Effort-related discounting (three versions including Rearing-Effort Discounting [RED] Task)

7. Fixed ratio discounting

\section{Rat (Selected references)}

Bussey et al. ${ }^{22}$ Markham et al. ${ }^{36}$ Aggleton et al. ${ }^{37}$

Talpos et al. ${ }^{39}$ Talpos et al. ${ }^{40}$

\section{Mouse (selected references)}

Bussey et al. ${ }^{24}$ Brigman et al. ${ }^{38}$

Clelland et al. ${ }^{41}$ Bartko et al. ${ }^{42}$

Nithianantharajah et al. ${ }^{43}$

Delotterie et al. ${ }^{44}$ Kim et al. ${ }^{45}$ Whoolery et al. ${ }^{46}$

Kenton et al. ${ }^{51} \mathrm{Kim}$ et al. $^{52}$

Talpos et al. ${ }^{47}$ McAllister et al. ${ }^{48}$

Hvoslef-Eide et al. ${ }^{49}$ Oomen et al. ${ }^{50}$

Bussey et al. 22

McTighe et al. $^{54}$

Bussey et al. ${ }^{22}$ Bussey et al. ${ }^{62}$ Chudasama et al. ${ }^{63}$ Janisiewicz and Baxter ${ }^{64}$

Talpos et al. ${ }^{66}$ Kumar et al. ${ }^{67}$

Bussey et al. $^{70}$

Broschard et al. ${ }^{71}$

-

Sahgal and Steckler ${ }^{23}$ Steckler and Sahgal ${ }^{74}$

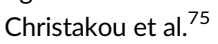

Mar et al. ${ }^{78}$ Ding et al. ${ }^{79}$

Braeckman et al. ${ }^{82}$

Wicks et al. ${ }^{83}$ Bangasser et al. ${ }^{84}$

- You and Mysore ${ }^{85}$

Cho et al. $2018^{87}$

Abela and Chudasama ${ }^{91,92}$

Abela and Chudasama ${ }^{91}$

$-$
Buscher et al. ${ }^{68}$

Kljakic et al. ${ }^{69}$

You and Mysore ${ }^{85}$

Li et al. $^{86}$

Clelland et al. ${ }^{41}$ Creer et al. ${ }^{56}$ Coba et al. ${ }^{57}$ Zhou et al. $^{58}$

Braida et al. ${ }^{59}$ Romberg et al. ${ }^{60}$ Reichelt et al. ${ }^{61}$

Delotterie et al. ${ }^{44}$ Princz-Lebel $^{65}$

Sliverman et al. ${ }^{72}$ Norris et al. ${ }^{73}$

Romberg et al. ${ }^{76}$ Kolisnyk et al. ${ }^{77}$

Kim et al. ${ }^{80}$ Hvoslef-Eide et al. ${ }^{81}$

Humby et al. ${ }^{88}$ Palmer (unpublished) ${ }^{89}$

Glover et al. ${ }^{90}$

Phillips (unpublished) ${ }^{93}$

Heath et al. ${ }^{94}$ Yang et al. ${ }^{95}$

Lopez-Cruz et al. $^{96}$

Lopez-Cruz et al. ${ }^{96}$ 
TABLE 1 (Continued)

\begin{tabular}{|c|c|c|}
\hline List of rodent touchscreen tests & Rat (Selected references) & Mouse (selected references) \\
\hline $\begin{array}{l}\text { D. Cognitive flexibility and response } \\
\text { inhibition: } \\
\text { 1. Reversal learning }\end{array}$ & $\begin{array}{l}\text { Bussey et al. }{ }^{97} \text { Chudasama et al. }{ }^{63} \\
\text { Chudasama and Robbins }\end{array}$ & $\begin{array}{l}\text { Brigman et al. }{ }^{99} \text { Izquierdo et al. }{ }^{100} \\
\text { Piantadosi et al. }{ }^{101}\end{array}$ \\
\hline 2. ID/ED Set-shifting & Brigman et al. ${ }^{99,38}$ Dickson et al. ${ }^{103,104}$ & McAllister ${ }^{105}$ \\
\hline $\begin{array}{l}\text { 3. Extinction Learning (response to } \\
\text { omission of reward) }\end{array}$ & $\begin{array}{l}\text { Dalley et al. }{ }^{106} \\
\text { Chudasama and Robbins }{ }^{98}\end{array}$ & $\begin{array}{l}\text { Brigman et al. }{ }^{107} \text { Hefner et al. }{ }^{108} \text { Lederle } \\
\text { et al. }{ }^{109}\end{array}$ \\
\hline 5. The STABFLEX task & - & Richter et al. ${ }^{112}$ \\
\hline \multicolumn{3}{|l|}{$\begin{array}{l}\text { E. Emotional cognition and responding to } \\
\text { reinforcement: }\end{array}$} \\
\hline $\begin{array}{l}\text { 1. Progressive ratio test of motivation/ } \\
\text { apathy }\end{array}$ & Hailwood et al. ${ }^{113}$ & Heath et al. ${ }^{94}$ Phillips et al. ${ }^{32}$ \\
\hline $\begin{array}{l}\text { 3. Autoshaping (Pavlovian approach to } \\
\text { reward; sign- and goal-tracking; }\end{array}$ & $\begin{array}{l}\text { Bussey et al. }{ }^{97} \text { Inglis et al. }{ }^{116} \text { Parkinson } \\
\text { et al. }{ }^{117} \text { Dalley et al. }{ }^{118}\end{array}$ & Nithianantharajah et al. ${ }^{43}$ \\
\hline $\begin{array}{l}\text { 4.Cognitive Judgment Bias (optimism/ } \\
\text { pessimism) }\end{array}$ & - & Krakenberg et al. ${ }^{120}$ \\
\hline
\end{tabular}

class of drug in Alzheimer's patients. ${ }^{76,124,125}$ More recently, a touchscreen-based progressive ratio task was used to establish that levels of motivation in an animal model of Huntington's disease (R6/1 mice) were comparable to Huntington's disease patients' motivational levels on a similar touchscreen-based version of the task. ${ }^{126}$ In addition, numerous studies highlight the similarity of findings across species on touchscreen tests of reversal learning (a test of cognitive flexibility). ${ }^{9}$

Consistent with the recognition by CNTRICS, NEWMEDS, the NIH Toolbox and RDoC that standardization of cognitive assessment tools is fundamental for driving translational research forward, touchscreen users have collaborated to develop standardized protocols for rodent touchscreen tasks. The Bussey-Saksida touchscreen system was commercialized in 2009 in response to increasing demand for access to the technology. Then, in 2013, Bussey, Saksida and colleagues published three invited papers in nature protocols, that contain detailed step-by-step instructions on how to prepare animals for pre-training in the apparatus, how to pretrain and train the animals and how to analyze the behavioral data. Also included are instructions on how to trouble-shoot in response to any issues that may arise. ${ }^{127-129}$ (See also a protocol paper for PR test of motivation/apathy published separately). ${ }^{130}$

It is relevant to note that these published protocols were the culmination of two decades of research to ensure the reliability and validity of the touchscreen cognitive testing method for rodents and the knowledge and insights gained during this process. The transparent sharing of methods, which was unique in so far as it predated recent calls for open science, afforded the possibility that other researchers could more readily implement the method in their own laboratories. These publications have also laid the groundwork for standardizing the touchscreen cognitive testing method across laboratories so that touchscreen experiments may be directly replicated, ultimately leading to more powerful discoveries. Indeed, use of the rodent touchscreen system has grown exponentially in the past two decades. In 2012, there were roughly 30 labs using the technology ${ }^{25}$; now, in 2020, over 300 different research groups in more than 200 research institutes in at least 26 countries are using the technology. Moreover, there has been a rapid and sustained increase in touchscreen publications over the last two decades (from about five per year in 2005 to over 40 in 2018). ${ }^{131}$

Our aims in the rest of the paper are to describe recent state-ofthe-art research at Western University combining the use of touchscreens with cutting-edge neurotechnology and open science platforms, and some similar exciting developments occurring in laboratories at other institutions.

\subsection{New frontiers in translation: MouseTRAP}

There is currently a pressing need to identify new approaches to developing more effective and specific treatments for cognitive impairments that accompany many neuropsychiatric, neurodegenerative and other brain disorders. One approach that holds great promise is to understand how dysfunctions in the molecular and cellular underpinnings of the brain impact those aspects of cognition-including memory, attention and cognitive flexibility-that are so profoundly affected in these disorders. Key to the success of this approach are tools that allow the assessment of cognition in animal models of disease in a way that is directly relevant to humans and that may be paired with cutting-edge neurotechnologies that allow neuronal, glial, 
and neurochemical activity to be manipulated and recorded with millisecond precision during cognitive assessment. This integrative approach may be used to determine which neural circuits underlie which aspects of cognition and to identify disruptions in neural circuitry that correlate with cognitive impairments. Therapeutic interventions that directly target these neural circuits may then be tested for efficacy in improving cognitive performance in animal models. Importantly, the success of this approach requires careful cognitive assessments of mouse models of disease in order to develop rigorous cognitive profiles that may then be directly compared to cognitive profiles of human patients they are designed to model, and that can be used to ground assessments of the potential efficacy of candidate therapeutic interventions.

MouseTRAP is a technologically innovative and methodologically integrative service platform operating out of the Rodent Cognition Core (RCC) at Western University that aims to realize this circuit-based approach to developing effective and specific treatments for brain disorders. The MouseTRAP platform features the largest collection of mouse touchscreens in the world, a wide range of animal models of neurodegenerative, neuropsychiatric and other brain disorders (e.g., concussion) and cutting-edge neurotechnologies for recording or manipulating neuronal, glial, and neurochemical activity with millisecond precision in animal models of disease during human-relevant cognitive performance.

MouseTRAP researchers are committed to the idea that open, accessible, and reproducible science is key to accelerating discovery in translational research. Given that the costs associated with implementing touchscreen technology may be prohibitive for some researchers, MouseTRAP democratizes access to these tools by offering academic and industry scientists varying levels of research support at different rates. MouseTRAP researchers can conduct a full touchscreen-based cognitive assessment in a mouse model of disease, provide researchers with training and access to state-of-the art equipment to run their own experiments on-site or offer them technical guidance to implement MouseTRAP tools in their own laboratories. In addition, interested researchers from around the globe also may take advantage of extensive knowledge and data-sharing resources available on two web-based science platforms that are integrated with MouseTRAP, touchscreencognition.org and mousebytes.ca.

Our aims in the rest of the paper are to describe in detail the distinctive features of MouseTRAP and the research it facilitates.

\subsection{1 | Developing complementary touchscreen cognitive assessment tools for rodents and humans}

The development of next-generation mouse models that bear greater genetic and functional similarity to their human patient counterparts provide a novel opportunity to use the touchscreen cognitive testing battery to provide cognitive profiles for these animals. These profiles may then be directly compared to the performance profiles of their human patient counterparts on a similar or nearly identical battery of touchscreen tests. MouseTRAP currently enables high-throughput assessment of cognition in up to 500 mice per day on more than
20 different cognitive tests developed by the Western team. Since the inception of the platform 2 years ago, 56 active phenotyping projects by 65 researchers have or are currently being undertaken using the platform.

Researchers working with animal models of neurodegenerative and neuropsychiatric disease affiliated with the CFREF-funded BrainsCAN Rodent Cognition Core at Western (https://brainscan. uwo.ca/research/cores/rodent_cognition_core/index.html), where about 100 touchscreens are currently housed are, in collaboration with researchers in Western's Imaging Core and researchers at Lawson Health Research Institute, iteratively developing a suite of tests that are adequately parameterized for rodents and humans. This comparative approach will enable researchers to determine the translational neurocognitive and predictive validity of the tests, as has been done in previous studies for animal models of schizophrenia, Huntington's disease, and Alzheimer's disease mentioned in the previous section. To ensure that the tests remain cutting edge, new tests are being developed and validated with emphasis on combining appropriate tests with mouse disease models.

\subsection{2 | The advantage of using mouse models}

Rodents are critical subjects for understanding causal relationships between molecular and circuit changes affecting cognitive function. They serve as one of the initial lines of enquiry in the quest to understand cognition in mammals, and can provide knowledge that can be taken forward to inform experiments in other species, such as nonhuman primates and humans. Although touchscreens for rodents were initially developed for rats, the availability of mouse touchscreens combined with the power of genetically modified mice has substantially multiplied the possibilities for translational rodent behavioral research (MouseTRAP is expanding to include rat experiments and mousebytes. ca [described below] accommodates the inclusion of data from rats).

Recent developments of genetic techniques have diversified genetic manipulations to multiple species, but mice remain the species of choice. In addition to being less expensive to maintain than rats, the sheer number and diversity of genetically-modified mice allows researchers to manipulate almost any neuronal circuit, by using a combination of floxed (flanked by lox P)-engineered mice, Cre recombinase mice, viral vectors and other intersectional genetic strategies. ${ }^{132,133}$ Thanks to multiple technological developments, including the use of CRISPR/Cas and viral technology, new viral vectors can be injected in the periphery to target specific groups of brain cells. ${ }^{134,135}$ An extensive description of all of these different technologies is beyond the scope of the present review, but we will briefly summarize how the use of these technologies combined with highlevel cognitive testing using touchscreens can reveal subtle and specific roles of genes and circuits in high-level cognition.

One gene recombination strategy is gene knock-out, which involves the replacement or elimination of genes to understand how loss of function or specific mutations affect cognition. Knockout of genes, specifically knockout of neurotransmitter receptors, metabolic 
enzymes and transporters, has been used extensively to provide information on the role of genes and gene products in behavior. Unfortunately, it is sometimes difficult to discern with constitutive knockouts if phenotypes are related to altered brain development. Moreover, if a gene is expressed in multiple brain regions or cellular types, it can be difficult to relate specific phenotypes to changes in genotype. Many of these limitations, however, can be ameliorated through the use of approaches such as Cre/lox technology, which allows for knockout or knockdown of genes in specific brain regions, cell types or in specific time windows, by using inducible and brain-region or cell-type specific promoters. This can be achieved either via a breeding strategy using Cre mouse lines, or via viral vectors expressing Cre. Viruses can be stereotaxically injected at specific ages and in specific brain regions, thus restricting the temporal and anatomical expression of the transduced gene. Cre mice can also be used to express opsins or Designer Receptors Exclusively Activated by Designer Drugs (DREADDS) in specific circuits, neuronal populations or glia cells. This approach allows for precise manipulations of circuits and cells, either by directly controlling electrical activity (mostly done with optogenetics) or by changing signaling pathways in distinct cell types (using DREADDS). ${ }^{136,137}$ However, one of the disadvantages of viral injections is lack of homogeneity, with variable levels of expression and targeted regions. There are also potential limitations of using transgenic mice, for example positional insertion of transgenes can influence expression levels and a number of Cre mice present mosaicism. ${ }^{132}$ Cre mice may present germ line recombination, causing deletion of floxed genes in germ cells, leading to overall deletion of one copy of the gene in all tissues. These issues can be mitigated by the careful selection of mouse lines (guidelines for optimal use of Cre transgenic lines are provided in $\operatorname{ref}^{132}$ ). The use of Cre knockin lines are particularly effective to prevent some of these confounds.

An important application of using knock-in approaches is the generation of mouse models of disease, in which gene mutations similar to the ones found in humans can be inserted in a targeted manner into the mouse genome. Alternatively, so-called 'humanized' knockin mouse models of disease feature modifications of whole mouse genes to match human genes. These knock-in approaches provide opportunities for understanding numerous neuropsychiatric and neurodegenerative disorders, without the disadvantages of older transgenic approaches (e.g., overexpression of gene products). The MouseTRAP platform thus uses knock-in models where possible. These models are particularly powerful when combined with cutting-edge neurotechnology and touchscreen behavioral testing. Using this combinatorial approach, both genes and cognitive tasks are "humanized", providing a powerful platform for translational understanding.

\subsection{3 | Combining the use of opsins and fluorescent biosensors with touchscreen-based cognitive assessment}

Thanks to the convergent development of optical-based techniques such as optogenetics, ${ }^{138,139}$ fiber photometry ${ }^{140}$ and miniscopes, ${ }^{141}$ which each respectively require the use of genetically engineered microbial opsins or fluorescent-based biosensors, we are able to manipulate and record activity of neural circuits underlying behavior at a cellular millisecond-scale resolution while animals freely move around and perform cognitive tests in touchscreens. Moreover, because touchscreens can accurately timestamp every significant event during training and probe sessions, it is possible to automatically trigger optogenetic stimulation or to correlate neural events with behavioral onset/offset, providing mechanistic insights into brain diseases.

Optogenetics is a neurotechnology that combines genetic and optical methods to manipulate the activity of discrete population of neurons in living tissue or in behaving animals. ${ }^{136}$ The success of this technology is attributable to several main features: (a) it allows the expression of genetically engineered microbial opsins that directly elicit rapid millisecond-scale inward or outward electrical currents across cellular membranes in response to pulses of light, (b) it may be used to target specific cell populations within the brain, and (c) it can be integrated with behavioral approaches, including automated touchscreen systems. ${ }^{136}$ As a result of the significant impact of using optogenetic technology in diverse fields in neuroscience and beyond, new microbial opsins have been found and genetically engineered to provide a wider spectrum of chimeric opsins with different channel kinetics, photocurrent magnitude and spectral sensitivity. ${ }^{142-144}$ These recent innovations in optogenetics have increased its suitability to be used in combination with fluorescent biosensors (discussed below) to simultaneously record neural activity of discrete populations in diverse brain regions. The latter have permitted an 'all-optical read-in and read-out' approach; as optogenetics and fiber photometry/miniscopes use the same optical devices to deliver light into discrete brain regions and even share similar TTL-triggering devices, a researcher can optogenetically stimulate and record neural activity simultaneously, which is highly desirable when using touchscreens.

Understanding the relevant brain network circuitry underlying behavior is fundamental for providing mechanistic insights into brain disease. However, as coordinated spatiotemporal firing patterns of neurons (e.g. spike sequence, spike frequency, temporal coding, spiketime synchrony) are thought to underlie cognition and learning, ${ }^{145}$ technologies that can report neural activity at the single-cell resolution while maintaining spatial information are necessary. Traditionally, in vivo electrophysiological techniques have been used to record neuronal activities at pre- and post-synaptic sites with high temporal resolution, yet while they allow the discrimination of heterogeneous populations of cells in discrete brain regions, they cannot be used to determine differences in the activity of neuronal subpopulations within those regions. In general, technologies that can pinpoint selective and real-time neural circuit dynamics with timescales relevant to the formation of behavioral outcomes are required. The development of optical tools such as fiber photometry ${ }^{140}$ and miniscopes ${ }^{141}$ also has allowed in vivo observation of targeted cells and their projections in freely behaving animals. This is a major advantage over the method of head-fixing animals to investigate and manipulate neural circuits in vivo, which induces physiological stress and reduces an animal's 
behavioral repertoire. ${ }^{26}$ Optical tools have become indispensable techniques in neuroscience when used in combination with fluorescent biosensors precisely because they allow the activity of selective populations of neurons to be correlated with behavioral performance without introducing these types of confounds. ${ }^{146}$

Fluorescent biosensors may be divided into two main groups. One group can be used to monitor neuronal activity (e.g., calcium and voltage). This kind of biosensor has been applied in multiple organisms including rodents, both healthy wild-type and disease models, ${ }^{147,148}$ and monkeys. ${ }^{149}$ Another group of biosensors can be used to detect extracellular neurotransmitters or neuromodulators with high sensitivity and specificity. ${ }^{150-154}$ It is widely known that neurotransmitters and neuromodulators play a key role in communication between neurons, and are involved in basically all physiological processes, including learning and memory, attention, emotion and movement. Neurotransmitter and neuromodulator malfunction is implicated in many neurodegenerative and neuropsychiatric diseases, such as the cholinergic system in Alzheimer's Disease ${ }^{155}$ and the serotoninergic system in depression. ${ }^{156}$ Optical methods have multiple advantages in detecting neuronal signals including: (a) cell-type specificity, when using genetically-encoded fluorescent biosensors; (b) high temporal and spatial resolution, which permits real-time observation of neuronal signals; and (c) limited damage to samples, especially in vivo, compared with traditional methods such as electrophysiological and biochemical techniques.

The MouseTRAP platform combines optical recording plus fluorescent biosensors with touchscreen-based cognitive assessment, providing the power to dissect the relationship between neuronal activities, neurochemical dynamics, and cognitive behaviors. These tools may be used to pinpoint neurochemical and population activity underlying specific stages or aspects of cognition with exquisite sensitivity and to identify disruptions in neural circuit activity that underlie impairments in behavioral performance in animal models of disease. They thus may provide important insights into which neuronal populations or circuits should be targeted for therapeutic intervention in neurodegenerative, neuropsychiatric and other brain disorders. They also may be used to determine if acute modulations of neural circuit function produce acute changes in behavioral performance in animal models, thus facilitating go-no-go decisions to advance drug discovery. ${ }^{157-159}$ MouseTRAP's emphasis on developing complementary cognitive assessment tools for rodents and humans in order to facilitate translation increases the likelihood that candidate interventions that are shown to enhance neural circuit function and positively impact behavioral performance in animal models of disease will have positive therapeutic potential in human patients.

\subsection{4 | Using computational models to inform analysis of cognitive/behavioral data}

When touchscreens are used in combination with sophisticated technologies for recording neuronal activity in vivo during active cognitive processes, a wealth of neural and behavioral data is produced, which creates new analytic and interpretative challenges. In order to address these challenges and illuminate the relationship between circuit activity and behavior during cognitive performance, touchscreen researchers and computational neuroscientists (Muller, Mofrad) working within the MouseTRAP platform are collaborating to develop novel techniques and models for data analysis. These computational tools will allow rich behavioral data to be linked to complex patterns of neural activity at the single-trial and moment-by-moment level and permit comparative analyses of circuit and behavioral activity across species, thereby facilitating effective translation to clinical application.

When analyzing experimental recordings with optical imaging techniques, a key consideration is to develop techniques that are robust to noise, ${ }^{102,160}$ but that also avoid the problems of signal attenuation that occur with trial averaging. ${ }^{161,162}$ By developing and applying signal processing techniques that are robust to noise, ${ }^{55}$ we can identify patterns of neural activity associated with cognitive processing, as well as their changes in neurodegenerative and neuropsychiatric disease. In addition, connecting these techniques to circuit models enables hypothesis-driven investigation of neural circuit dynamics during cognitive tasks in health and disease, and these network models can further help with the interpretation of optogenetic perturbations. This combined computational modeling and analysis approach can thus connect changes in observed brain dynamics to single-neuron and network properties, allowing for the identification of mechanisms underlying cognitive deficits and potential targets for therapeutic intervention.

\subsection{5 | Open science platforms and epistemic community building}

A major component of the MouseTRAP philosophy is that revolutionary advances in translational research require large-scale collaboration among research teams composed of members with diverse training backgrounds and technical expertise. Yet what truly sets MouseTRAP apart from other collaborative translational research initiatives is the emphasis its researchers place on the importance of prepublication knowledge and data-sharing practices to create a community of scientists who share common methodology and are united in the goals of increasing methodological transparency and improving the reliability and reproducibility of research findings. In order to foster the development of such a collaborative epistemic community surrounding touchscreen use, we have created two open access platforms, touchscreencognition.org (Dumont and Ansari) and mousebytes.ca (Memar). As we explain, the extensive resources offered on these platforms are unprecedented in rodent behavioral research and far exceed information about methods and data typically made available in the methods and results sections of published research papers. 


\subsection{6 | Touchscreencognition.org}

Touchscreencognition.org (Figure 1) is a web-based platform for knowledge sharing and community building that allows researchers to work collaboratively and troubleshoot common problems that may arise when conducting touchscreen based cognitive assessments that otherwise may have taken individual research groups more time to solve. Furthermore, more individuals working with similar goals in optimizing rodent cognitive testing, developing best practices, and enhancing current standardization practices may serve to improve the quality and reproducibility of research and ideally lead to greater clinical translation. An additional goal of touchscreencognition.org is to provide resources to scientists who have expertise in nonbehavioral areas of neuroscience, ensuring that they can combine their knowledge and methodologies with high-quality cognitive testing. Touchscreencognition.org is available to all touchscreen enthusiasts regardless of experience level or type of touchscreen technology used for cognitive testing. Indeed, while most researchers on touchscreencognition.org use rodent models, a minority of (much welcomed!) researchers study less common animal models (e.g., pigs).

There are numerous features on the touchscreencognition.org platforms that center on community building and knowledge mobilization. First, there is a resource section where touchscreen users can gain access to task-specific standard operating procedures (SOPs). The resource section also contains training videos with information on how to run an experiment beginning with setting up a database to extracting data for upload into MouseBytes.ca (described below), training on touchscreen maintenance as well as some "Tips \& Tricks"

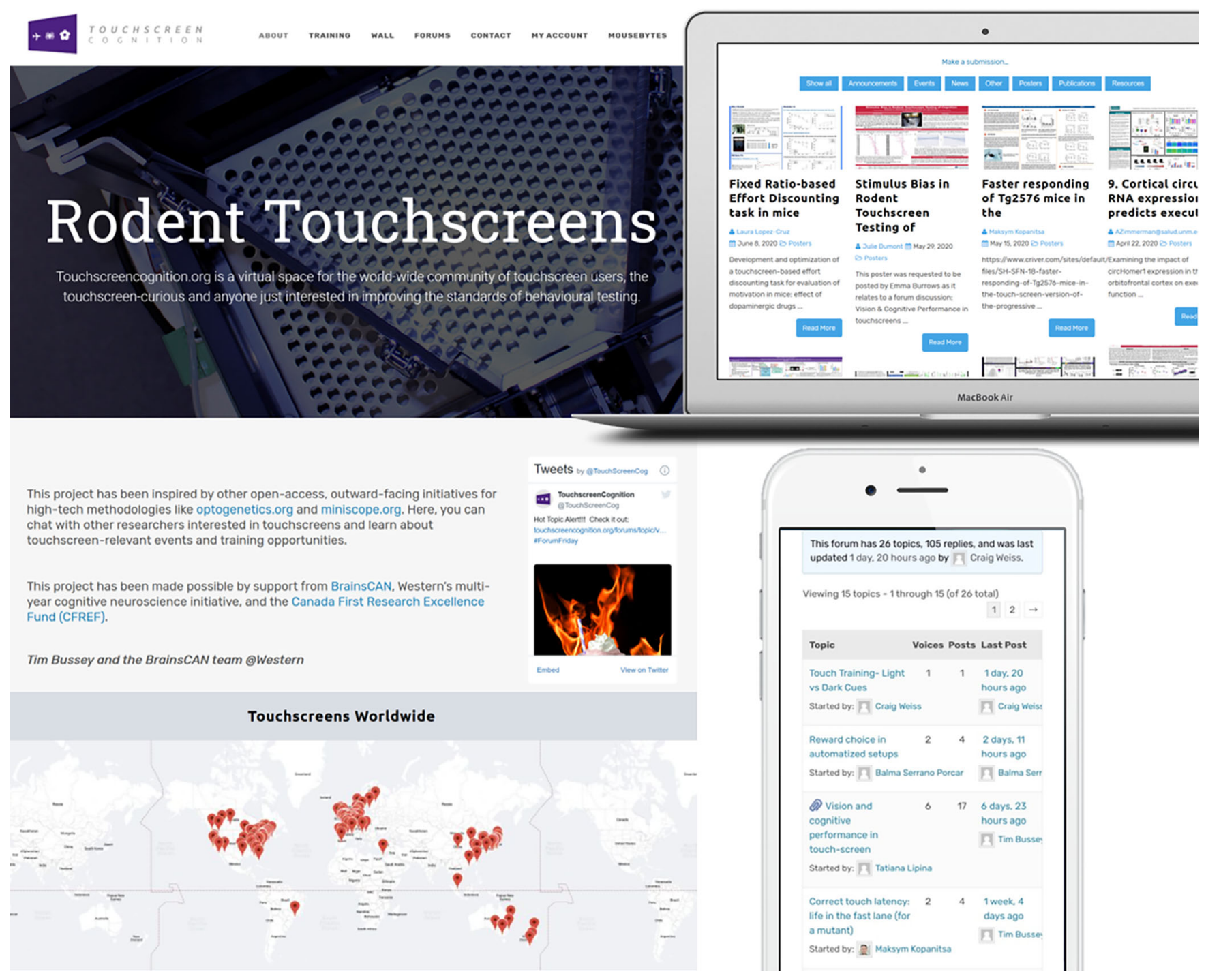

FIGURE 1 The touchscreencognition.org virtual space. Clockwise from left, (A) The main page for touchscreencognition.org, containing links to different parts of the site including the training sessions we offer and how to set up a user account; (B) the Wall, where contributors may share recently published or presented touchscreen related research; $(C)$ the Forums page, where touchscreen users can post touchscreen related questions and receive responses from the global touchscreen community; (D) A global map representing all of the laboratories worldwide that use rodent touchscreens. (E) Information about funding support for the site as well as a link to @TouchScreenCog's Twitter feed 
for common troubleshooting. This section also includes information on our events (past and present) to join our hands on, in-person, training workshops as well as our annual touchscreen symposium. ${ }^{9}$ The 2020 Symposium, including short talks and posters, was conducted virtually and attended by scientists from around the world. Most of the talks from graduate students to principal investigators are available on the past events section of the site. In addition to these resources, more community building features are included. Notably, there is the "Wall" where scientists can post their recent touchscreenrelated publications, posters, resources, events, and even job postings. However, the most interactive portion of the website is the Forum where touchscreen users can ask and respond to questions or comment on the latest touchscreen news, tasks, and technological upgrades. The active touchscreen community encourages a continued expansion of the features found on touchscreencognition.org in order to meet its needs. To stay informed on the touchscreen community and changes to touchscreencognition.org, a new quarterly newsletter was recently launched, thus furthering the goal of knowledge sharing and expanding the sense of community for touchscreen enthusiasts and users.

\section{MouseBytes ${ }^{163}$}

To leverage the development of standardized cognitive assessment tools and their increased use at multiple research sites, the first ever open-access database (mousebytes.ca) ${ }^{29}$ for rodent translational research was developed by a neuroinformatics specialist (Memar) and touchscreen researchers at Western University. It is a fundamental step towards data availability, transparency and reproducibility. As Figure 2 shows, the proposed open-access and user-friendly repository employs advanced web technologies and connects to a database of cognitive data, allowing researchers across the globe to pre-process, run automated quality control scripts on, visualize, and analyze their data alone or alongside other researchers' stored data. A unique link, generated for each analysis for sharing the data, can be added to publications for redirecting researchers to MouseBytes. Conversely, the DOI of a published manuscript can be linked to datasets to facilitate that retrieval from a study. Users can set the status of their data/ experiment as either private or public in MouseBytes. Data with public status can be shared under CCO license, allowing a researcher to reuse, re-analyze and share the data without any restriction. Researchers may opt instead to keep their data private, and the accessibility and usage of that data will be limited to its owner and those with whom the owner shares that data. Public data in MouseBytes are integrated to the analytics TIBCO SPOTFIRE (https://www.tibco. com/products/tibco-spotfire) to generate an interactive visualization platform for a variety of cognitive tasks. An overview of MouseBytes data, number of labs, principle investigators and datasets in the

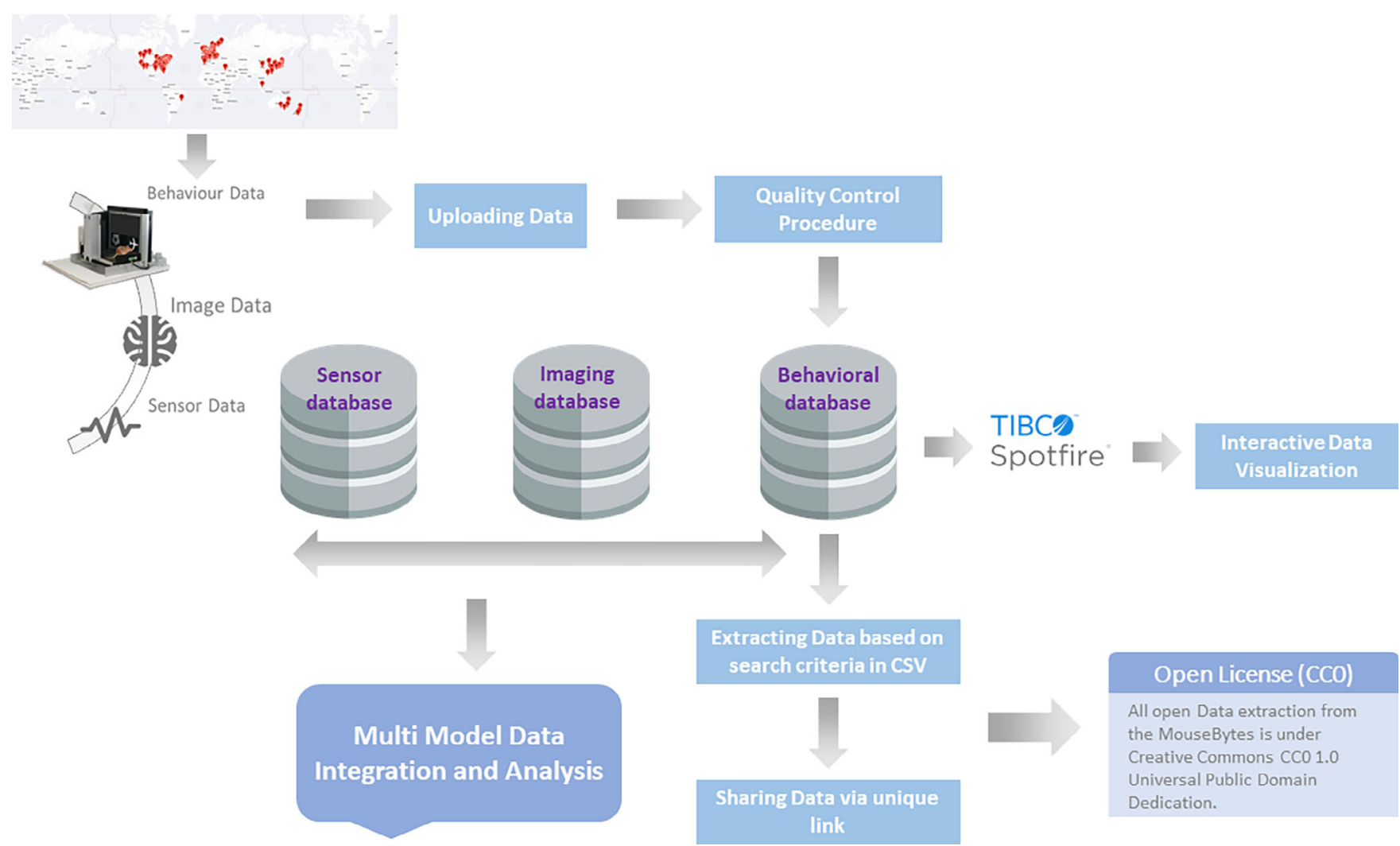

FIGURE 2 MouseBytes Data Integration and Sharing Flow Diagram: Uploading cognitive behavioral data is followed by quality control in order to transfer valid and complete data into the database. Public data can be searched based on different search criteria and shared using the generated unique URL. Public data in the database are also integrated with their MRI data and sensor data from fiber photometry to increase the functionality and use of MouseBytes and facilitate multimodality data integration and analysis 
proposed repository can be found at the following link: (https:// mousebytes.ca/mb-dashboard).

Furthermore, expanding mousebytes by incorporating neuroimaging data and recording of neural activity in behaving mice, as well as developing algorithms to allow data analysis from a variety of species, will facilitate comprehensive multi-modal cognitive analysis to accelerate discovery across disease contexts. Combined with another new initiative, PubScreen-which allows interrogation of touchscreenrelated outputs using search terms including brain regions, neurotransmitters, drugs, techniques, etc. - these open-science tools will help to advance knowledge- and data-sharing and improve the understanding of neural mechanisms of brain function in health and disease.

\subsection{The circuits to cognition initiative and future directions}

We began this paper with the identification of a set of benchmarks for translational cognitive neuroscience research and emphasized that meeting them required collaboration among investigators having diverse training backgrounds and complementary technical expertise. In addition to our previous research and that currently being undertaken at Western, we have also begun an exciting partnership with researchers at McGill University to unite neuroscience researchers across these institutions as part of a broader global initiative (Circuits to Cognition; $\mathrm{C2C}$ ) aimed at illuminating the neural mechanisms of cognition and accelerating forward translational research. MouseTRAP and a complementary touchscreen-based Open Science platform at McGill, the McGill-Mouse-Miniscope (M3) Platform, also described in this special issue ${ }^{119}$ are core components of this initiative.

What sets the $\mathrm{C} 2 \mathrm{C}$ initiative apart is a commitment to integrating standardized touchscreen-based cognitive assessment techniques with complementary techniques to investigate neural activity at multiple levels of analysis from genes to behavior. Whereas researchers at Western are combining genetic techniques and fiber photometry to investigate molecular and neurochemical changes in vivo while mice perform touchscreen-based tasks, McGill researchers are combining miniscopes with the use of genetically encoded calcium indicators (GECls) to visualize calcium activity in vivo as mice perform touchscreen-based tasks. Just as Western researchers are investigating molecular and neurochemical changes in mouse models of disease, McGill researchers plan to investigate neuronal population dynamics in mouse models of disease and determine abnormal patterns of activity that underlie cognitive deficits in these mouse models. The M3 Platform, like MouseTRAP, also functions as a service platform insofar as it provides guidelines and technical support for researchers from other institutions to record neuronal dynamics in vivo in mice during touchscreen-based tasks and to upload and share their data.

Our collaboration with McGill researchers is only the beginning. Given the global rise in combining touchscreen technology with stateof-the art neurotechnology and increased collaboration among diverse research groups using touchscreens, illuminating the neural mechanisms of cognition and identifying novel therapeutics to treat cognitive impairments in neuropsychiatric, neurodegenerative and other brain disorders are on the horizon.

\section{ACKNOWLEDGMENTS}

Cambridge Enterprise, the technology transfer office of the University of Cambridge, supported commercialization of the Bussey-Saksida chamber, culminating in a license to Campden Instruments. Any financial compensation received from commercialization of the technology is fully invested in further touchscreen development and/or maintenance.

This research was supported by BrainsCAN at Western University through the Canada First Research Excellence Fund (CFREF). LMS is a CIFAR Fellow in the Brain, Mind and Consciousness program.

This research also was supported by a Western University Strategic Support for Tri-Council Success Grant and a Social Science and Humanities Research Council Insight Grant awarded to JAS, LMS and TJB.

\section{DATA AVAILABILITY STATEMENT}

N/A.

\section{ORCID}

Jacqueline A. Sullivan (D) https://orcid.org/0000-0003-3042-4632

Julie R. Dumont (D) https://orcid.org/0000-0002-2412-306X

Yulong Li (D) https://orcid.org/0000-0002-9166-9919

Lyle Muller (D) https://orcid.org/0000-0001-5165-9890

Vania F. Prado (D) https://orcid.org/0000-0003-4994-6393

Marco A. M. Prado (D) https://orcid.org/0000-0002-3028-5778

Lisa M. Saksida (D) https://orcid.org/0000-0002-8416-8171

Timothy J. Bussey (D) https://orcid.org/0000-0001-7518-4041

\section{REFERENCES}

1. International Brain Laboratory. An international laboratory for systems and computational neuroscience. Neuron. 2017;96(6):12131218. https://doi.org/10.1016/j.neuron.2017.12.013.

2. Carter CS, Barch DM. Cognitive neuroscience-based approaches to measuring and improving treatment effects on cognition in schizophrenia: the CNTRICS initiative. Schizophr Bull. 2007;33(5):11311137. https://doi.org/10.1093/schbul/sbm081.

3. Moore H, Geyer MA, Carter CS, Barch DM. Harnessing cognitive neuroscience to develop new treatments for improving cognition in schizophrenia: CNTRICS selected cognitive paradigms for animal models. Neurosci Biobehav Rev. 2013;37(9 Pt B):2087-2091. https:// doi.org/10.1016/j.neubiorev.2013.09.011.

4. StensbøI TB, Kapur S. NEWMEDS special issue commentary. Psychopharmacology (Berl). 2015;232(21-22):3849-3851. https://doi.org/ 10.1007/s00213-015-4083-y.

5. Hodes RJ, Insel TR, Landis SC. NIH blueprint for neuroscience research. The NIH toolbox: setting a standard for biomedical research. Neurology. 2013;80(11):S1. https://doi.org/10.1212/WNL. Ob013e3182872e90.

6. Weintraub S, Dikmen SS, Heaton RK, et al. Cognition assessment using the NIH toolbox. Neurology. 2013;80(11):S54-S64. https://doi. org/10.1212/WNL.0b013e3182872ded.

7. Insel T, Cuthbert B, Garvey $M$, et al. Research domain criteria (RDoC): toward a new classification framework for research on 
mental disorders. Am J Psychiatry. 2010;167(7):748-751. https://doi. org/10.1176/appi.ajp.2010.09091379.

8. Cuthbert BN, Kozak MJ. Constructing constructs for psychopathology: the nimh research domain criteria. J Abnorm Psychol. 2013;122 (3):928-937. https://doi.org/10.1037/a0034028.

9. Hvoslef-Eide M, Nilsson S, Saksida L, Bussey T. Cognitive translation using the rodent touchscreen testing approach. Curr Topics Behav Neurosci. 2016;28:423-447.

10. Barch D, Carter C, Arnsten A, et al. Selecting paradigms from cognitive neuroscience for translation into use in clinical trials: proceedings of the third CNTRICS meeting. Schizophr Bull. 2009;35(1): 109-114.

11. Brooks S, Dunnett S. Tests to assess motor phenotype in mice: a user's guide. Nat Rev Neurosci. 2009;10:519-529.

12. Churchland PS, Sejnowski TJ. Perspectives on cognitive neuroscience. Science. 1988;242(4879):741-745. https://doi.org/10.1126/ science.3055294.

13. Weiskrantz L. Trying to bridge some neuropsychological gaps between monkey and man. $\mathrm{Br} J$ Psychol. 1977;68(4):431-445. https://doi.org/10.1111/j.2044-8295.1977.tb01609.x.

14. Roberts A, Sahakian B. Comparable tests of cognitive function in monkey and man. A. Saghal (Ed.), Behavioural Neuroscience: A Practical Approach. Vol 1. Oxford, England: Oxford University Press; 1993: 165-184.

15. Sahakian BJ, Owen AM. Computerized assessment in neuropsychiatry using CANTAB: discussion paper. J R Soc Med. 1992;85(7):399-402.

16. Fray $P$, Robbins $T$, Sahakian B. Neuropsychiatric applications of CANTAB. Intl J Geriatric Psychiatry. 1996;11:329-336.

17. Morris RG, Downes JJ, Sahakian BJ, Evenden JL, Heald A, Robbins TW. Planning and spatial working memory in Parkinson's disease. J Neurol Neurosurg Psychiatry. 1988;51(6):757-766. https:// doi.org/10.1136/jnnp.51.6.757.

18. Sahakian BJ, Morris RG, Evenden JL, et al. A comparative study of visuospatial memory and learning in Alzheimer-type dementia and Parkinson's disease. Brain. 1988;111(Pt 3):695-718. https://doi.org/ 10.1093/brain/111.3.695.

19. Robbins TW, James M, Owen AM, Sahakian BJ, Mclnnes L, Rabbitt P. Cambridge neuropsychological test automated battery (CANTAB): a factor analytic study of a large sample of normal elderly volunteers. Dementia. 1994;5(5):266-281. https://doi.org/10.1159/ 000106735.

20. Klingberg T, Fernell E, Olesen PJ, et al. Computerized training of working memory in children with ADHD-a randomized, controlled trial. J Am Acad Child Adolesc Psychiatry. 2005;44(2):177-186. https://doi.org/10.1097/00004583-200502000-00010.

21. Chacko A, Bedard AC, Marks DJ, et al. A randomized clinical trial of Cogmed working memory training in school-age children with ADHD: a replication in a diverse sample using a control condition. J Child Psychol Psychiatry. 2014;55(3):247-255. https://doi.org/10. 1111/jcpp.12146.

22. Bussey T, Muir J, Robbins T. A novel automated touchscreen procedure for assessing learning in the rat using computer graphic stimuli. Neuroscience Res Communications. 1994;15(2):103-110.

23. Sahgal A, Steckler T. TouchWindows and operant behaviour in rats. J Neurosci Methods. 1994;55(1):59-64. https://doi.org/10.1016/ 0165-0270(94)90041-8.

24. Bussey TJ, Saksida LM, Rothblat LA. Discrimination of computergraphic stimuli by mice: a method for the behavioral characterization of transgenic and gene-knockout models. Behav Neurosci. 2001;115 (4):957-960. https://doi.org/10.1037//0735-7044.115.4.957.

25. Bussey TJ, Holmes A, Lyon L, et al. New translational assays for preclinical modelling of cognition in schizophrenia: the touchscreen testing method for mice and rats. Neuropharmacology. 2012;62(3): 1191-1203. https://doi.org/10.1016/j.neuropharm.2011.04.011.
26. Juczewski K, Koussa J, Kesner A, Lee J, Lovinger D. Stress and behavioral correlates in the head-fixed method doi: https://doi.org/ 10.1101/2020.02.24.963371

27. livonen H, Nurminen L, Harri M, Tanila H, Puoliväli J. Hypothermia in mice tested in Morris water maze. Behav Brain Res. 2003;141(2): 207-213. https://doi.org/10.1016/s0166-4328(02)00369-8.

28. Janickova $\mathrm{H}$, Kljakic $\mathrm{O}$, Rosborough $\mathrm{K}$, et al. Selective decrease of cholinergic signaling from pedunculopontine and laterodorsal tegmental nuclei has little impact on cognition but markedly increases susceptibility to stress. FASEB J. 2019;33(6):7018-7036. https://doi. org/10.1096/fj.201802108R.

29. Morton AJ, Skillings E, Bussey TJ, Saksida LM. Measuring cognitive deficits in disabled mice using an automated interactive touchscreen system. Nat Methods. 2006;3(10):767. https://doi.org/10.1038/ nmeth1006-767.

30. Bussey TJ, Padain TL, Skillings EA, Winters BD, Morton AJ, Saksida LM. The touchscreen cognitive testing method for rodents: how to get the best out of your rat. Learn Mem. 2008;15(7):516523. https://doi.org/10.1101/Im.987808.

31. Graybeal C, Bachu M, Mozhui K, et al. Strains and stressors: an analysis of touchscreen learning in genetically diverse mouse strains. PLoS One. 2014;9(2):e87745. https://doi.org/10.1371/journal.pone. 0087745.

32. Phillips BU, Heath CJ, Ossowska Z, Bussey TJ, Saksida LM. Optimisation of cognitive performance in rodent operant (touchscreen) testing: evaluation and effects of reinforcer strength. Learn Behav. 2017;45(3):252-262. https://doi.org/10.3758/s13420-017-0260-7.

33. Kim EW, Phillips BU, Heath CJ, et al. Optimizing reproducibility of operant testing through reinforcer standardization: identification of key nutritional constituents determining reward strength in touchscreens. Mol Brain. 2017;10(1):31. https://doi.org/10.1186/ s13041-017-0312-0.

34. Shansky RM, Woolley CS. Considering sex as a biological variable will be valuable for neuroscience research. J Neurosci. 2016;36(47): 11817-11822. https://doi.org/10.1523/JNEUROSCI.1390-16.2016.

35. Shansky RM. Are hormones a "female problem" for animal research? Science. 2019;364(6443):825-826. https://doi.org/10.1126/science. aaw7570.

36. Markham MR, Butt AE, Dougher MJ. A computer touch-screen apparatus for training visual discriminations in rats. J Exp Anal Behav. 1996;65(1):173-182. https://doi.org/10.1901/jeab.1996.65-173.

37. Aggleton JP, Keen S, Warburton EC, Bussey TJ. Extensive cytotoxic lesions involving both the rhinal cortices and area TE impair recognition but spare spatial alternation in the rat. Brain Res Bull. 1997;43 (3):279-287. https://doi.org/10.1016/s0361-9230(97)00007-5.

38. Brigman JL, Bussey TJ, Saksida LM, Rothblat LA. Discrimination of multidimensional visual stimuli by mice: intra- and extradimensional shifts. Behav Neurosci. 2005;119(3):839-842. https://doi.org/10. 1037/0735-7044.119.3.839.

39. Talpos JC, Winters BD, Dias R, Saksida LM, Bussey TJ. A novel touchscreen-automated paired-associate learning (PAL) task sensitive to pharmacological manipulation of the hippocampus: a translational rodent model of cognitive impairments in neurodegenerative disease. Psychopharmacology (Berl). 2009;205(1):157-168. https:// doi.org/10.1007/s00213-009-1526-3.

40. Talpos JC, Aerts N, Fellini L, Steckler T. A touch-screen based paired-associates learning (PAL) task for the rat may provide a translatable pharmacological model of human cognitive impairment. Pharmacol Biochem Behav. 2014;122:97-106. https://doi.org/10. 1016/j.pbb.2014.03.014.

41. Clelland $C D$, Choi M, Romberg $C$, et al. A functional role for adult hippocampal neurogenesis in spatial pattern separation. Science. 2009;325(5937):210-213. https://doi.org/10.1126/science. 1173215. 
42. Bartko SJ, Vendrell I, Saksida LM, Bussey TJ. A computer-automated touchscreen paired-associates learning (PAL) task for mice: impairments following administration of scopolamine or dicyclomine and improvements following donepezil. Psychopharmacology (Berl). 2011; 214(2):537-548. https://doi.org/10.1007/s00213-010-2050-1.

43. Nithianantharajah J, Komiyama NH, McKechanie A, et al. Synaptic scaffold evolution generated components of vertebrate cognitive complexity. Nat Neurosci. 2013;16(1):16-24. https://doi.org/10. 1038/nn.3276.

44. Delotterie D, Mathis C, Cassel JC, Dorner-Ciossek C, Marti A. Optimization of touchscreen-based behavioral paradigms in mice: implications for building a battery of tasks taxing learning and memory functions. PLoS One. 2014;9(6):e100817. https://doi.org/10.1371/ journal.pone.0100817.

45. Kim J, Wasserman EA, Castro L, Freeman JH. Anterior cingulate cortex inactivation impairs rodent visual selective attention and prospective memory. Behav Neurosci. 2016;130(1):75-90. https://doi. org/10.1037/bne0000117.

46. Whoolery CW, Yun S, Reynolds RP, et al. Multi-domain cognitive assessment of male mice shows space radiation is not harmful to high-level cognition and actually improves pattern separation. Sci Rep. 2020;10(1):2737. https://doi.org/10.1038/s41598-02059419-z.

47. Talpos JC, McTighe SM, Dias R, Saksida LM, Bussey TJ. Trial-unique, delayed nonmatching-to-location (TUNL): a novel, highly hippocampus-dependent automated touchscreen test of location memory and pattern separation. Neurobiol Learn Mem. 2010;94(3): 341-352. https://doi.org/10.1016/j.nlm.2010.07.006.

48. McAllister KA, Saksida LM, Bussey TJ. Dissociation between memory retention across a delay and pattern separation following medial prefrontal cortex lesions in the touchscreen TUNL task. Neurobiol Learn Mem. 2013;101:120-126. https://doi.org/10.1016/j.nlm. 2013.01.010.

49. Hvoslef-Eide M, Oomen CA, Fisher BM, et al. Facilitation of spatial working memory performance following intra-prefrontal cortical administration of the adrenergic alpha1 agonist phenylephrine. Psychopharmacology (Berl). 2015;232(21-22):4005-4016. https://doi. org/10.1007/s00213-015-4038-3.

50. Oomen CA, Hvoslef-Eide M, Kofink D, et al. A novel 2- and 3-choice touchscreen-based continuous trial-unique nonmatching-to-location task (cTUNL) sensitive to functional differences between dentate gyrus and CA3 subregions of the hippocampus. Psychopharmacology (Berl). 2015;232(21-22):3921-3933. https://doi.org/10.1007/ s00213-015-4019-6.

51. Kenton JA, Castillo R, Holmes A, Brigman JL. Cortico-hippocampal GluN2B is essential for efficient visual-spatial discrimination learning in a touchscreen paradigm. Neurobiol Learn Mem. 2018;156:60-67. https://doi.org/10.1016/j.nlm.2018.10.011.

52. Kim CH, Romberg C, Hvoslef-Eide $M$, et al. Trial-unique, delayed nonmatching-to-location (TUNL) touchscreen testing for mice: sensitivity to dorsal hippocampal dysfunction. Psychopharmacology (Berl). 2015;232(21-22):3935-3945. https://doi.org/10.1007/s00213015-4017-8.

53. Kwak C, Lim CS, Kaang BK. Development of a touch-screen-based paradigm for assessing working memory in the mouse. Exp Neurobiol. 2015;24(1):84-89. https://doi.org/10.5607/en.2015.24.1.84.

54. McTighe SM, Mar AC, Romberg C, Bussey TJ, Saksida LM. A new touchscreen test of pattern separation: effect of hippocampal lesions. Neuroreport. 2009;20(9):881-885. https://doi.org/10.1097/ WNR.0b013e32832c5eb2.

55. Chemla S, Muller L, Reynaud A, Takerkart S, Destexhe A, Chavane F. Improving voltage-sensitive dye imaging: with a little help from computational approaches. Neurophotonics. 2017;4(3):031215. https:// doi.org/10.1117/1.NPh.4.3.031215.
56. Creer DJ, Romberg C, Saksida LM, Praag H, Bussey TJ. Running enhances spatial pattern separation in mice. Proc Natl Acad Sci U S A. 2010;107(5):2367-2372. https://doi.org/10.1073/pnas. 0911725107.

57. Coba MP, Komiyama NH, Nithianantharajah J, et al. TNiK is required for postsynaptic and nuclear signaling pathways and cognitive function. J Neurosci. 2012;32(40):13987-13999. https://doi.org/10. 1523/JNEUROSCI.2433-12.2012.

58. Zhuo JM, Tseng HA, Desai M, et al. Young adult born neurons enhance hippocampal dependent performance via influences on bilateral networks. Elife. 2016;5:e22429. https://doi.org/10.7554/ elife.22429.

59. Braida D, Donzelli A, Martucci R, et al. Mice discriminate between stationary and moving 2D shapes: application to the object recognition task to increase attention. Behav Brain Res. 2013;242:95-101. https://doi.org/10.1016/j.bbr.2012.12.040.

60. Romberg C, McTighe SM, Heath CJ, et al. False recognition in a mouse model of Alzheimer's disease: rescue with sensory restriction and memantine. Brain. 2012;135(Pt 7):2103-2114. https://doi.org/ 10.1093/brain/aws074.

61. Reichelt AC, Palmer D, Shaikh S, Bussey TJ, Saksida LM. Optimization of a touchscreen spontaneous object recognition task for optogenetics in mice. The Canadian Association for Neuroscience 2019 Scientific Program. Toronto, Ontario, Canada: The Canadian Association for Neuroscience; 2019.

62. Bussey TJ, Duck J, Muir JL, Aggleton JP. Distinct patterns of behavioural impairments resulting from fornix transection or neurotoxic lesions of the perirhinal and postrhinal cortices in the rat. Behav Brain Res. 2000;111(1-2):187-202. https://doi.org/10.1016/s01664328(00)00155-8.

63. Chudasama Y, Bussey TJ, Muir JL. Effects of selective thalamic and prelimbic cortex lesions on two types of visual discrimination and reversal learning. Eur J Neurosci. 2001;14(6):1009-1020. https://doi. org/10.1046/j.0953-816x.2001.01607.x.

64. Janisiewicz AM, Baxter MG. Transfer effects and conditional learning in rats with selective lesions of medial septal/diagonal band cholinergic neurons. Behav Neurosci. 2003;117(6):1342-1352. https:// doi.org/10.1037/0735-7044.117.6.1342.

65. Princz-Lebel $O$, Wasserman $D$, Skirzewski $M$, MacDonald $P$, Bussey T, Saksida L. Optimization of the touchscreen-based visuomotor conditional learning task in mice. The Canadian Association for Neuroscience (CAN-ACN) 2019 Scientific Program. Toronto, Ontario, Canada: The Canadian Association for Neuroscience; 2019.

66. Talpos JC, Dias R, Bussey TJ, Saksida LM. Hippocampal lesions in rats impair learning and memory for locations on a touch-sensitive computer screen: the "ASAT" task. Behav Brain Res. 2008;192(2): 216-225. https://doi.org/10.1016/j.bbr.2008.04.008.

67. Kumar G, Talpos J, Steckler T. Strain-dependent effects on acquisition and reversal of visual and spatial tasks in a rat touchscreen battery of cognition. Physiol Behav. 2015;144:26-36. https://doi.org/ 10.1016/j.physbeh.2015.03.001.

68. Buscher N, van Dorsselaer P, Steckler T, Talpos JC. Evaluating aged mice in three touchscreen tests that differ in visual demands: impaired cognitive function and impaired visual abilities. Behav Brain Res. 2017;333:142-149. https://doi.org/10.1016/j.bbr.2017. 06.053.

69. Kljakic O, Janickova H, Skirzewski Prieto M, et al. Motivation and Cue-Directed Effort Are Regulated by Acetylcholine/Glutamate CoTransmission from Striatal Cholinergic Interneurons. London, Ontario, Canada: International Touchscreen Symposium: Virtual Edition; 2020.

70. Bussey TJ, Clea Warburton E, Aggleton JP, Muir JL. Fornix lesions can facilitate acquisition of the transverse patterning task: a challenge for "configural" theories of hippocampal function. J Neurosci. 
1998;18(4):1622-1631. https://doi.org/10.1523/JNEUROSCI.1804-01622.1998.

71. Broschard MB, Kim J, Love BC, Freeman JH. Category learning in rodents using touchscreen-based tasks. Genes Brain Behav. 2021;20: e12665. https://doi.org/10.1111/gbb.12665.

72. Silverman JL, Gastrell PT, Karras MN, Solomon M, Crawley JN. Cognitive abilities on transitive inference using a novel touchscreen technology for mice. Cereb Cortex. 2015;25(5):1133-1142. https:// doi.org/10.1093/cercor/bht293.

73. Norris RHC, Churilov L, Hannan AJ, Nithianantharajah J. Mutations in neuroligin-3 in male mice impact behavioral flexibility but not relational memory in a touchscreen test of visual transitive inference. Mol Autism. 2019;10:42. https://doi.org/10.1186/s13229-0190292-2.

74. Steckler T, Sahgal A. Psychopharmacological studies in rats responding at touch-sensitive devices. Psychopharmacology (Berl). 1995;118(2):226-229. https://doi.org/10.1007/BF02245846.

75. Christakou A, Robbins TW, Everitt BJ. Functional disconnection of a prefrontal cortical-dorsal striatal system disrupts choice reaction time performance: implications for attentional function. Behav Neurosci. 2001;115(4):812-825. https://doi.org/10.1037//0735-7044. 115.4.812.

76. Romberg C, Mattson MP, Mughal MR, Bussey TJ, Saksida LM. Impaired attention in the 3xTgAD mouse model of Alzheimer's disease: rescue by donepezil (Aricept). J Neurosci. 2011;31(9):35003507. https://doi.org/10.1523/JNEUROSCI.5242-10.2011.

77. Kolisnyk B, Al-Onaizi MA, Hirata PH, et al. Forebrain deletion of the vesicular acetylcholine transporter results in deficits in executive function, metabolic, and RNA splicing abnormalities in the prefrontal cortex. J Neurosci. 2013;33(37):14908-14920. https://doi.org/10. 1523/JNEUROSCl.1933-13.2013.

78. Mar AC, Nilsson SRO, Gamallo-Lana B, et al. MAM-E17 rat model impairments on a novel continuous performance task: effects of potential cognitive enhancing drugs. Psychopharmacology (Berl). 2017;234(19):2837-2857. https://doi.org/10.1007/s00213-0174679-5.

79. Ding Z, Brown JW, Rueter LE, Mohler EG. Profiling attention and cognition enhancing drugs in a rat touchscreen-based continuous performance test. Psychopharmacology (Berl). 2018;235(4):10931105. https://doi.org/10.1007/s00213-017-4827-y.

80. Kim CH, Hvoslef-Eide M, Nilsson SR, et al. The continuous performance test (rCPT) for mice: a novel operant touchscreen test of attentional function. Psychopharmacology (Berl). 2015;232(21-22): 3947-3966. https://doi.org/10.1007/s00213-015-4081-0.

81. Hvoslef-Eide M, Nilsson SR, Hailwood JM, et al. Effects of anterior cingulate cortex lesions on a continuous performance task for mice. Brain Neurosci Adv. 2018;2398212818772962:2. https://doi.org/10. $1177 / 2398212818772962$.

82. Braeckman K, Descamps B, Vanhove C, Caeyenberghs K. Exploratory relationships between cognitive improvements and training induced plasticity in hippocampus and cingulum in a rat model of mild traumatic brain injury: a diffusion MRI study. Brain Imaging Behav. 2019. https://doi.org/10.1007/s11682-019-00179-4.

83. Wicks B, Waxler DE, White KM, et al. Method for testing sustained attention in touchscreen operant chambers in rats. J Neurosci Methods. 2017;277:30-37. https://doi.org/10.1016/j.jneumeth. 2016.12.003.

84. Bangasser DA, Wicks B, Waxler DE, Eck SR. Touchscreen sustained attention task (SAT) for rats. J Vis Exp. 2017;(127):56219. https:// doi.org/10.3791/56219.

85. You WK, Mysore SP. Endogenous and exogenous control of visuospatial selective attention in freely behaving mice. Nat Commun. 2020;11(1):1986. https://doi.org/10.1038/s41467-020-15909-2.

86. Li S, May C, Hannan, AJ, et al. Assessing Attention Orienting in Mice: a novel touchscreen adaptation of the posner-style cueing task. https://www.biorxiv.org/content/biorxiv/early/2020/06/06/2020. 06.05.136689.full.pdf

87. Cho BR, Kwak MJ, Kim WY, Kim JH. Impulsive action and impulsive choice are differentially expressed in rats depending on the age at exposure to a gambling task. Front Psych. 2018;9:503. https://doi. org/10.3389/fpsyt.2018.00503.

88. Humby T, Smith GE, Small R, et al. Effects of 5-HT2C, 5-HT1A receptor challenges and modafinil on the initiation and persistence of gambling behaviours. Psychopharmacology (Berl). 2020;237(6): 1745-1756. https://doi.org/10.1007/s00213-020-05496-x.

89. Palmer, D. Role of medial and lateral orbitofrontal cortex in gambling-based decision making.

90. Glover LR, Postle AF, Holmes A. Touchscreen-based assessment of risky-choice in mice. Behav Brain Res. 2020;112748393 https://doi. org/10.1016/j.bbr.2020.112748.

91. Abela AR, Chudasama Y. Dissociable contributions of the ventral hippocampus and orbitofrontal cortex to decision-making with a delayed or uncertain outcome. Eur J Neurosci. 2013;37(4):640-647. https://doi.org/10.1111/ejn.12071.

92. Abela AR, Chudasama Y. Noradrenergic $\alpha 2 A$-receptor stimulation in the ventral hippocampus reduces impulsive decision-making. Psychopharmacology (Berl). 2014;231(3):521-531. https://doi.org/10.1007/ s00213-013-3262-y.

93. Phillips B. Touchscreen Assessment of Motivation and ReinforcementRelated Choice Behaviour in Mice. Doctoral Dissertation. University of Cambridge: Cambridge, UK; 2018.

94. Heath CJ, Bussey TJ, Saksida LM. Motivational assessment of mice using the touchscreen operant testing system: effects of dopaminergic drugs. Psychopharmacology (Berl). 2015;232(21-22):4043-4057. https://doi.org/10.1007/s00213-015-4009-8.

95. Yang JH, Presby RE, Jarvie AA, et al. Pharmacological studies of effort-related decision making using mouse touchscreen procedures: effects of dopamine antagonism do not resemble reinforcer devaluation by removal of food restriction. Psychopharmacology (Berl). 2020;237(1):33-43. https://doi.org/10.1007/s00213-01905343-8.

96. Lopez-Cruz L, Phillips Bu, Hailwood JM. (2017) Development and optimization of a touchscreen-based effort discounting task for evaluation of motivation in mice: effect of dopaminergic drugs.

97. Bussey TJ, Muir JL, Everitt BJ, Robbins TW. Triple dissociation of anterior cingulate, posterior cingulate, and medial frontal cortices on visual discrimination tasks using a touchscreen testing procedure for the rat. Behav Neurosci. 1997;111(5):920-936. https://doi.org/10. 1037//0735-7044.111.5.920.

98. Chudasama $\mathrm{Y}$, Robbins TW. Dissociable contributions of the orbitofrontal and infralimbic cortex to pavlovian autoshaping and discrimination reversal learning: further evidence for the functional heterogeneity of the rodent frontal cortex. J Neurosci. 2003;23(25):87718780. https://doi.org/10.1523/JNEUROSCI.23-25-08771.2003.

99. Brigman JL, Padukiewicz KE, Sutherland ML, Rothblat LA. Executive functions in the heterozygous reeler mouse model of schizophrenia. Behav Neurosci. 2006;120(4):984-988. https://doi.org/10.1037/ 0735-7044.120.4.984.

100. Izquierdo A, Wiedholz LM, Millstein RA, et al. Genetic and dopaminergic modulation of reversal learning in a touchscreen-based operant procedure for mice. Behav Brain Res. 2006;171(2):181-188. https://doi.org/10.1016/j.bbr.2006.03.029.

101. Piantadosi PT, Lieberman AG, Pickens CL, Bergstrom HC, Holmes A. A novel multichoice touchscreen paradigm for assessing cognitive flexibility in mice. Learn Mem. 2018;26(1):24-30. https://doi.org/10. 1101/Im.048264.118.

102. Reynaud A, Takerkart S, Masson GS, Chavane F. Linear model decomposition for voltage-sensitive dye imaging signals: application in awake behaving monkey. Neuroimage. 2011;54(2):1196-1210. https://doi.org/10.1016/j.neuroimage.2010.08.041. 
103. Dickson PE, Calton MA, Mittleman G. Performance of C57BL/6J and $\mathrm{DBA} / 2 \mathrm{~J}$ mice on a touchscreen-based attentional set-shifting task. Behav Brain Res. 2014;261:158-170. https://doi.org/10.1016/ j.bbr.2013.12.015.

104. Dickson PE, Cairns J, Goldowitz D, Mittleman G. Cerebellar contribution to higher and lower order rule learning and cognitive flexibility in mice. Neuroscience. 2017;345:99-109. https://doi.org/10. 1016/j.neuroscience.2016.03.040.

105. McAllister KAL. Development and Validation of Touchscreen Automated Tasks to Assess Cognition in Preclinical Models of Schizophrenia. Cambridge UK: Doctoral Dissertation, University of Cambridge; 2012.

106. Dalley JW, Chudasama Y, Theobald DE, Pettifer CL, Fletcher CM, Robbins TW. Nucleus accumbens dopamine and discriminated approach learning: interactive effects of 6-hydroxydopamine lesions and systemic apomorphine administration. Psychopharmacology (Berl). 2002;161(4):425-433. https://doi.org/10.1007/s00213-0021078-2.

107. Brigman JL, Feyder M, Saksida LM, Bussey TJ, Mishina M, Holmes A. Impaired discrimination learning in mice lacking the NMDA receptor NR2A subunit. Learn Mem. 2008;15(2):50-54. https://doi.org/10.1101//m.777308.

108. Hefner K, Whittle N, Juhasz J, et al. Impaired fear extinction learning and cortico-amygdala circuit abnormalities in a common genetic mouse strain. J Neurosci. 2008;28(32):8074-8085. https://doi.org/ 10.1523/JNEUROSCI.4904-07.2008.

109. Lederle L, Weber S, Wright T, et al. Reward-related behavioral paradigms for addiction research in the mouse: performance of common inbred strains. PLoS One. 2011;6(1):e15536. https://doi.org/10. 1371/journal.pone.0015536.

110. Ahn JR, Lee I. Intact CA3 in the hippocampus is only sufficient for contextual behavior based on well-learned and unaltered visual background. Hippocampus. 2014;24(9):1081-1093. https://doi.org/ 10.1002/hipo.22292.

111. Rutz HL, Rothblat LA. Intact and impaired executive abilities in the BTBR mouse model of autism. Behav Brain Res. 2012;234(1):33-37. https://doi.org/10.1016/j.bbr.2012.05.048.

112. Richter SH, Vogel AS, Ueltzhöffer K, et al. Touchscreen-paradigm for mice reveals cross-species evidence for an antagonistic relationship of cognitive flexibility and stability. Front Behav Neurosci. 2014; 8:154. https://doi.org/10.3389/fnbeh.2014.00154.

113. Hailwood JM, Heath CJ, Robbins TW, Saksida LM, Bussey TJ. Validation and optimisation of a touchscreen progressive ratio test of motivation in male rats. Psychopharmacology (Berl). 2018;235(9): 2739-2753. https://doi.org/10.1007/s00213-018-4969-6.

114. Wilkinson MP, Grogan JP, Mellor JR, Robinson ESJ. Comparison of conventional and rapid-acting antidepressants in a rodent probabilistic reversal learning task. Brain Neurosci Adv. 2020;4: 2398212820907177. https://doi.org/10.1177/239821282090 7177.

115. Phillips BU, Dewan S, Nilsson SRO, et al. Selective effects of 5-HT2C receptor modulation on performance of a novel valenceprobe visual discrimination task and probabilistic reversal learning in mice. Psychopharmacology (Berl). 2018;235(7):2101-2111. https:// doi.org/10.1007/s00213-018-4907-7.

116. Inglis WL, Olmstead MC, Robbins TW. Pedunculopontine tegmental nucleus lesions impair stimulus-reward learning in autoshaping and conditioned reinforcement paradigms. Behav Neurosci. 2000;114(2): 285-294. https://doi.org/10.1037//0735-7044.114.2.285.

117. Parkinson JA, Willoughby PJ, Robbins TW, Everitt BJ. Disconnection of the anterior cingulate cortex and nucleus accumbens core impairs Pavlovian approach behavior: further evidence for limbic corticalventral striatopallidal systems. Behav Neurosci. 2000;114(1):42-63.

118. Dalley JW, Lääne $K$, Theobald DE, et al. Time-limited modulation of appetitive Pavlovian memory by D1 and NMDA receptors in the nucleus accumbens. Proc Natl Acad Sci U S A. 2005;102(17):61896194. https://doi.org/10.1073/pnas.0502080102.

119. Mosser C-A, Haqqee Z, Nieto-Posadas A, Murai K, Stifani S, Williams S, Brandon MP. The McGill-Mouse-Miniscope platform: A standardized approach for high-throughput imaging of neuronal dynamics during behavior. Genes, Brain and Behavior. 2021;20: e12686. https://doi.org/10.1111/gbb.12686.

120. Krakenberg V, von Kortzfleisch VT, Kaiser S, Sachser N, Richter SH. Differential effects of serotonin transporter genotype on anxietylike behavior and cognitive judgment Bias in mice. Front Behav Neurosci. 2019;13:263. https://doi.org/10.3389/fnbeh.2019.00263.

121. Romberg C, Horner AE, Bussey TJ, Saksida LM. A touch screenautomated cognitive test battery reveals impaired attention, memory abnormalities, and increased response inhibition in the TgCRND8 mouse model of Alzheimer's disease. Neurobiol Aging. 2013;34(3):731-744. https://doi.org/10.1016/j.neurobiolaging. 2012.08.006.

122. Hvoslef-Eide M, Mar AC, Nilsson SR, et al. The NEWMEDS rodent touchscreen test battery for cognition relevant to schizophrenia. Psychopharmacology (Berl). 2015;232(21-22):3853-3872. https:// doi.org/10.1007/s00213-015-4007-x.

123. Nithianantharajah J, McKechanie AG, Stewart TJ, et al. Bridging the translational divide: identical cognitive touchscreen testing in mice and humans carrying mutations in a disease-relevant homologous gene. Sci Rep. 2015;5:14613. https://doi.org/10.1038/srep14613.

124. Romberg C, Bussey TJ, Saksida LM. Paying more attention to attention: towards more comprehensive cognitive translation using mouse models of Alzheimer's disease. Brain Res Bull. 2013;92:49-55. https://doi.org/10.1016/j.brainresbull.2012.02.007.

125. Sahakian BJ, Coull JT. Tetrahydroaminoacridine (THA) in Alzheimer's disease: an assessment of attentional and mnemonic function using CANTAB. Acta Neurol Scand Suppl. 1993;149:29-35. https://doi. org/10.1111/j.1600-0404.1993.tb04251.x.

126. Heath CJ, O'Callaghan C, Mason SL, et al. A touchscreen motivation assessment evaluated in Huntington's disease patients and R6/1 model mice. Front Neurol. 2019;10:858. https://doi.org/10.3389/ fneur.2019.00858.

127. Horner AE, Heath $\mathrm{CJ}$, Hvoslef-Eide M, et al. The touchscreen operant platform for testing learning and memory in rats and mice. Nat Protoc. 2013;8(10):1961-1984. https://doi.org/10.1038/nprot. 2013.122.

128. Mar AC, Horner AE, Nilsson SR, et al. The touchscreen operant platform for assessing executive function in rats and mice. Nat Protoc. 2013;8(10):1985-2005. https://doi.org/10.1038/nprot.2013.123.

129. Oomen CA, Hvoslef-Eide M, Heath CJ, et al. The touchscreen operant platform for testing working memory and pattern separation in rats and mice. Nat Protoc. 2013;8(10):2006-2021. https://doi.org/ 10.1038/nprot.2013.124.

130. Heath C, Phillips B, Bussey T, Saksida L. Measuring motivation and reward-related decision making in the rodent operant touchscreen system. Curr Protoc Neurosci. 2016;74(8.34):1-8.

131. Dumont JR, Salewski R, Beraldo F. Critical mass: the rise of a touchscreen technology community for rodent cognitive testing. Genes Brain Behav. 2021;20:e12650. https://doi.org/10.1111/gbb. 12650.

132. Luo L, Ambrozkiewicz MC, Benseler F, et al. Optimizing nervous system-specific gene targeting with Cre driver lines: prevalence of Germline recombination and influencing factors. Neuron. 2020;106 (1):37-65.e5. https://doi.org/10.1016/j.neuron.2020.01.008.

133. Madisen L, Garner AR, Shimaoka D, et al. Transgenic mice for intersectional targeting of neural sensors and effectors with high specificity and performance. Neuron. 2015;85(5):942-958. https:// doi.org/10.1016/j.neuron.2015.02.022.

134. Chan KY, Jang MJ, Yoo BB, et al. Engineered AAVs for efficient noninvasive gene delivery to the central and peripheral nervous 
systems. Nat Neurosci. 2017;20(8):1172-1179. https://doi.org/10. 1038/nn.4593.

135. Deverman BE, Pravdo PL, Simpson BP, et al. Cre-dependent selection yields $A A V$ variants for widespread gene transfer to the adult brain. Nat Biotechnol. 2016;34(2):204-209. https://doi.org/10. 1038/nbt.3440.

136. Deisseroth K. Optogenetics. Nat Methods. 2011;8(1):26-29. https:// doi.org/10.1038/nmeth.f.324.

137. Roth BL. DREADDs for neuroscientists. Neuron. 2016;89(4):683694. https://doi.org/10.1016/j.neuron.2016.01.040.

138. Boyden ES, Zhang F, Bamberg E, Nagel G, Deisseroth K. Millisecond-timescale, genetically targeted optical control of neural activity. Nat Neurosci. 2005;8(9):1263-1268. https://doi.org/10.1038/ nn1525.

139. Deisseroth K. Optogenetics: 10 years of microbial opsins in neuroscience. Nat Neurosci. 2015;18(9):1213-1225. https://doi.org/10. 1038/nn.4091.

140. Gunaydin LA, Grosenick L, Finkelstein JC, et al. Natural neural projection dynamics underlying social behavior. Cell. 2014;157(7):15351551. https://doi.org/10.1016/j.cell.2014.05.017.

141. Ghosh KK, Burns LD, Cocker ED, et al. Miniaturized integration of a fluorescence microscope. Nat Methods. 2011;8(10):871-878. https://doi.org/10.1038/nmeth.1694.

142. Gradinaru V, Zhang F, Ramakrishnan C, et al. Molecular and cellular approaches for diversifying and extending optogenetics. Cell. 2010; 141(1):154-165. https://doi.org/10.1016/j.cell.2010.02.037.

143. Chuong AS, Miri ML, Busskamp V, et al. Noninvasive optical inhibition with a red-shifted microbial rhodopsin. Nat Neurosci. 2014;17 (8):1123-1129. https://doi.org/10.1038/nn.3752.

144. Deisseroth K, Hegemann P. The form and function of channelrhodopsin. Science. 2017;357(6356):5544. https://doi.org/10. 1126/science.aan5544.

145. Stein RB, Gossen ER, Jones KE. Neuronal variability: noise or part of the signal? Nat Rev Neurosci. 2005;6(5):389-397. https://doi.org/10. 1038/nrn1668.

146. Jing M, Zhang Y, Wang H, Li Y. G-protein-coupled receptor-based sensors for imaging neurochemicals with high sensitivity and specificity. J Neurochem. 2019;151(3):279-288. https://doi.org/10.1111/ jnc. 14855.

147. Chen TW, Wardill TJ, Sun Y, et al. Ultrasensitive fluorescent proteins for imaging neuronal activity. Nature. 2013;499(7458):295300. https://doi.org/10.1038/nature12354.

148. Piatkevich KD, Bensussen S, Tseng HA, et al. Population imaging of neural activity in awake behaving mice. Nature. 2019;574(7778): 413-417. https://doi.org/10.1038/s41586-019-1641-1.

149. Sadakane O, Masamizu Y, Watakabe A, et al. Long-term two-photon calcium imaging of neuronal populations with subcellular resolution in adult non-human Primates. Cell Rep. 2015;13(9):1989-1999. https://doi.org/10.1016/j.celrep.2015.10.050.

150. Marvin JS, Borghuis BG, Tian L, et al. An optimized fluorescent probe for visualizing glutamate neurotransmission. Nat Methods. 2013;10(2):162-170. https://doi.org/10.1038/nmeth.2333.
151. Jing $M$, Zhang $P$, Wang $G$, et al. A genetically encoded fluorescent acetylcholine indicator for in vitro and in vivo studies. Nat Biotechnol. 2018;36(8):726-737. https://doi.org/10.1038/nbt.4184.

152. Patriarchi T, Cho JR, Merten K, et al. Ultrafast neuronal imaging of dopamine dynamics with designed genetically encoded sensors. Science. 2018;360(6396):4422. https://doi.org/10.1126/science.aat4422.

153. Sun F, Zeng J, Jing $M$, et al. A genetically encoded fluorescent sensor enables rapid and specific detection of dopamine in flies, fish, and mice. Cell. 2018;174(2):481-496.e19. https://doi.org/10.1016/j. cell.2018.06.042.

154. Feng J, Zhang C, Lischinsky JE, et al. A genetically encoded fluorescent sensor for rapid and specific in vivo detection of norepinephrine. Neuron. 2019;102(4):745-761.e8. https://doi.org/10.1016/j. neuron.2019.02.037.

155. Ferreira-Vieira TH, Guimaraes IM, Silva FR, Ribeiro FM. Alzheimer's disease: targeting the cholinergic system. Curr Neuropharmacol. 2016;14(1): 101-115. https://doi.org/10.2174/1570159x13666150716165726.

156. Cowen PJ, Browning M. What has serotonin to do with depression? World Psychiatry. 2015;14(2):158-160. https://doi.org/10.1002/wps.20229.

157. Tye KM. Neural circuit reprogramming: a new paradigm for treating neuropsychiatric disease? Neuron. 2014;83(6):1259-1261. https:// doi.org/10.1016/j.neuron.2014.08.022.

158. Calhoon GG, Tye KM. Resolving the neural circuits of anxiety. Nat Neurosci. 2015;18(10):1394-1404. https://doi.org/10.1038/nn.4101.

159. Werner CT, Williams CJ, Fermelia MR, Lin DT, Li Y. Circuit mechanisms of neurodegenerative diseases: a new frontier with miniature fluorescence microscopy. Front Neurosci. 2019;13:1174. https://doi. org/10.3389/fnins.2019.01174.

160. Chemla S, Chavane F. Voltage-sensitive dye imaging: technique review and models. J Physiol Paris. 2010;104(1-2):40-50. https:// doi.org/10.1016/j.jphysparis.2009.11.009.

161. Alexander DM, Jurica $P$, Trengove $C$, et al. Traveling waves and trial averaging: the nature of single-trial and averaged brain responses in large-scale cortical signals. Neuroimage. 2013;73:95-112. https:// doi.org/10.1016/j.neuroimage.2013.01.016.

162. Muller L, Reynaud A, Chavane F, Destexhe A. The stimulus-evoked population response in visual cortex of awake monkey is a propagating wave. Nat Commun. 2014;5:3675. https://doi.org/10.1038/ncomms4675.

163. Beraldo FH, Palmer D, Memar S, et al. MouseBytes, an open-access high-throughput pipeline and database for rodent touchscreenbased cognitive assessment. Elife. 2019;8:e49630. https://doi.org/ 10.7554/eLife.49630.

How to cite this article: Sullivan JA, Dumont JR, Memar S, et al. New frontiers in translational research: Touchscreens, open science, and the mouse translational research accelerator platform. Genes, Brain and Behavior. 2021;20:e12705. https:// doi.org/10.1111/gbb.12705 